Article

\title{
Cryogenic Energy for Indirect Freeze Desalination-Numerical and Experimental Investigation
}

\author{
Harith Jayakody *, Raya Al-Dadah and Saad Mahmoud \\ School of Mechanical Engineering, University of Birmingham, Birmingham B152TT, UK; \\ r.k.al-dadah@bham.ac.uk (R.A.-D.); s.m.mahmoud@bham.ac.uk (S.M.) \\ * Correspondence: harith_ej@hotmail.com
}

Received: 24 November 2019; Accepted: 18 December 2019; Published: 21 December 2019

\begin{abstract}
Renewed interest in freeze desalination has emerged due to its advantages over other desalination technologies. A major advantage of the freeze desalination process over evaporative methods is its lower energy consumption (latent heat of freezing is $333.5 \mathrm{~kJ} / \mathrm{kg}$ and latent heat of evaporation is $2256.7 \mathrm{~kJ} / \mathrm{kg}$ ). Cryogenic fluids like $\mathrm{LN}_{2} / \mathrm{L}_{\mathrm{Air}}$ are emerging as an effective energy storage medium to maximise utilisation of intermittent renewable energy sources. The recovery of this stored cold energy has the potential to be used for freeze desalination. Computational Fluid Dynamics (CFD) modelling was developed to simulate the evaporation of liquid nitrogen to simultaneously conduct freeze desalination to investigate the feasibility of using cryogenic energy for freeze desalination. This integrated CFD model was validated using experimental heat exchanger test facility constructed, to evaporate liquid nitrogen to supply the cooling required for freezing. Parametric study on the $\mathrm{LN}_{2}$ flow rate to observe the volume of ice obtained was also examined using CFD, where increasing the velocity of $\mathrm{LN}_{2}$ by 6 times, increased the volume of ice obtained by 4.3 times. A number of freezing stages were required in order to reduce the ice salinity from $1.5 \%$ down to $0.1 \%$ as regarded by the World Health Organisation (WHO) as safe to drink. In the cryogenic desalination test rig, approximately $1.35 \mathrm{~L}$ of liquid nitrogen was required to reduce the ice salinity from $1.5 \%$ to less than $0.1 \%$. Furthermore, the above results illustrate the potential of using the cold energy of cryogenic fluids such as Liquified Natural Gas (LNG) and $\mathrm{LN}_{2} / \mathrm{L}_{\mathrm{Air}}$ for freeze desalination applications as most cold energy during LNG regasification has been unexploited today.
\end{abstract}

Keywords: cryogenic energy; liquid nitrogen; CFD; freeze; desalination

\section{Introduction}

Sustainable resources of water and energy are essential for social, economic and human wellbeing in the modern world [1]. The basic substance for life is water, and it is progressively becoming a scarce resource with half of the population of about 88 developing countries affected by water shortages [2]. In these developing countries, $80 \%$ to $90 \%$ of all diseases are caused by poor water quality and $30 \%$ deaths are also due to poor water quality [2]. The people affected by harsh water shortages are projected to rise in the next 25 years due to the growth in population and the demands of industrialization [3]. At present, the rate of increase of water consumption is twice the rate of population growth, where it doubles every 20 years [4]. There is a vast amount of water available on Earth, about $1.4 \times 10^{9} \mathrm{~km}^{3}$ [4]. However, less than $3 \%$ of this amount is fresh water, about $3.5 \times 10^{7} \mathrm{~km}^{3}$. A major part of this (about $2.4 \times 10^{7} \mathrm{~km}^{3}$ ) is not accessible due to it being located in ice caps and glaciers. Approximately, $1.1 \times 10^{7} \mathrm{~km}^{3}$ of the Earth's water is retained as groundwater, plants, atmosphere and surface water in rivers, lakes, etc. [5]. The greatest part of this water has slowly accrued over time, and it is not 
considered to be renewable [2]. Freshwater production by the removal of dissolved minerals from seawater is known as desalination, and it appears to be an answer to the water shortage issue $[6,7]$. Cost-effective and possibly climate independent water resources can be produced by desalination technologies for agricultural uses [8]. In order to address the water shortage issue, seawater is the leading feed water in the world for installed desalination techniques, thus making it the most applied solution [8].

Freeze desalination (FD) is an evolving desalination technology due to its low energy usage. In comparison to other desalination techniques, FD has several advantages [9-14]. In freeze desalination, the salts are rejected during ice formation and ice formed is of pure water where the crystal lattice does not allow the inclusion of any salts due to the nature of the ice crystal structure $[9,10]$. The process of freezing an aqueous salt solution results in ice crystals that are of pure water in the solid phase; this process is the physical principle of freeze desalination [15]. The Low energy usage is achieved in the FD process due to the latent heat of fusion being about $335 \mathrm{~kJ} / \mathrm{kg}$ while the latent heat of vaporization is about $2256.7 \mathrm{~kJ} / \mathrm{kg}[11,12]$. Another key advantage of the freeze desalination process is its low operating cost of $0.34 \$ / \mathrm{m}^{3}$ compared to $0.75 \$ / \mathrm{m}^{3}$ for the commonly used Reverse Osmosis (RO) desalination technology. A key advantage of the freeze desalination technology is the ability to utilize the cold energy from the regasification of liquefied natural gas (LNG). This high-quality cold energy source can be used to freeze saltwater in the freeze desalination process, but most cold energy during LNG regasification has been unexploited until today. Approximately $830 \mathrm{~kJ} / \mathrm{kg}$ of cold energy is released during LNG regasification and this cryogenic exergy can be used for the freeze desalination process [16]. Due to the on-going energy supply-demand disparity, augmenting these technologies can aid in providing solutions for this and in improving the economics of the renewable energy powered desalination systems, as desalination capacity is escalating worldwide [17].

Research has been carried out experimentally and numerically on ice formation on subcooled surfaces for the rate of ice growth and conditions for control [18], temperature distribution [19], heat transfer coefficient [20], unsteady heat transfer [21], and ice growth kinetics for a continuous freezing process $[22,23]$. Nonetheless, this research did not include the progression of salt separation and the increase of brine salinity in the remaining solution. Abid et al. [24] studied the separation of binary mixture freezing for saltwater desalination, but the effect of saline water ice growth dynamics was not investigated widely. During the FD process, the separation of salt from ice and the rise of brine salinity in the remaining solution were not studied by other researchers.

Energy storage is a vital part of energy production, using renewable energy sources [25]. Cryogenic energy offers better exploitation of renewable energy, due to the fact that liquid nitrogen and liquid air are known to be important energy carriers in the recent past. This is mainly due to the high energy density and the availability of cryogenic energy. Cryogenic energy storage uses surplus electricity to cool air to liquefy it, and then, it is stored in tanks. Liquid air can be stored in a compact manner in small tanks because of the energy density and pressure. In low pressure insulated tanks, these cryogenic fluids can be stored for months with losses as small as $0.005 \%$ volume per day [26]. When needed, the liquid air is pressurized and transformed into gaseous state (evaporated), usually using waste heat from another process (higher temperature source). This gas is then expanded to run a turbine to generate electricity [26,27].

The novelty of this research is the study of evaporation of liquid nitrogen for freeze desalination. Many researchers have looked into the use of cryogenics as a source of energy for many applications such as cooling for domestic and industrial processes and driving turbines and engines for power generation, etc. [28-32]. Cryogenic energy has also been utilised in freeze desalination by few researchers $[14,16,33]$. However, numerical modelling of cryogenic energy for freeze desalination has not yet been studied, and the use of the evaporation of liquid nitrogen for indirect contact freeze desalination has not yet been investigated. Therefore, this paper focuses on the evaporation of liquid nitrogen for indirect contact freeze desalination. Computational fluid dynamics (CFD) analysis of this 
process was carried out, and an experimental test rig was built to further understand this process and to validate the CFD model.

\section{CFD Modelling Theory}

Literature on CFD modelling of the evaporation of liquid nitrogen process and the freeze desalination process is very limited. Therefore, CFD modelling of the evaporation of liquid nitrogen as a source of cooling for the freeze desalination process was established. In this paper, 3D CFD simulations were developed to simulate the evaporation of liquid nitrogen to simultaneously conduct freeze desalination. The modelling theories of the evaporation of liquid nitrogen process and of the freeze desalination process are discussed in this paper.

\subsection{Evaporation of Liquid Nitrogen Theory}

Liquid nitrogen turns from liquid to nitrogen gas in the evaporation process of $\mathrm{LN}_{2}$. Therefore, for modelling the evaporation process where the fluid changes phase (liquid to gas), the multiphase model in ANSYS Fluent (19.1, ANSYS, Canonsburg, Pennsylvania, United States, 2018) is used. Additionally, the energy and the turbulent models were used to determine temperature variation during the turbulent flow of the fluid. In the ANSYS multiphase module, three different Euler-Euler multiphase models are offered: the Eulerian model, the mixture model and the volume of fluid (VOF) model [34]. All of these Euler-Euler multiphase models can be used to model the evaporation of liquid nitrogen. However, only the volume of fluid (VOF) can be used in conjunction with the solidification/melting model that is used to model the freeze desalination process. Therefore, when simulating the evaporation of liquid nitrogen simultaneously with the freeze desalination modelling, only the VOF option in the multiphase model can be used.

By solving a single set of momentum equations and tracking the volume fraction of each of the fluids in the field, the VOF model is able to model two or more immiscible fluids [34]. Key processes that the VOF model is able to model are steady/transient tracking of any liquid-gas interface, motion of bubbles in a liquid, prediction of jet breakup, etc. [34].

In the VOF model, the tracking of the interfaces between the phases is achieved by using the continuity equation for the volume fraction of one or more of the phases. Hence, Equation (1) represents this for the $q^{\text {th }}$ phase [34].

$$
\frac{1}{\rho_{q}}\left[\frac{d}{d t}\left(\alpha_{q} \rho_{q}\right)+\nabla .\left(\alpha_{q} \rho_{q} \vec{v}_{q}\right)=S_{\alpha_{q}}+\sum_{p=1}^{n}\left(\dot{m}_{p q}-\dot{m}_{q p}\right)\right]
$$

where the mass transfer from phase $p$ to phase $q$ is denoted as $\dot{m}_{p q}$, and the mass transfer from phase $q$ to phase $p$ is denoted as $\dot{m}_{q p} . S_{\alpha_{q}}$ is a source term which is zero by default, but a user-defined mass source for each phase can be specified.

For the primary phase, the volume fraction equation is not solved; based on the following constraint, the primary-phase volume fraction is calculated as $\sum_{q=1}^{n} \alpha_{q}=1$. Through implicit or explicit time discretization, the volume fraction equation is solved [34].

In the VOF model, a single momentum equation is solved, and the subsequent velocity field is shared amid the phases. The momentum equation is dependent on the volume fractions of all phases via the properties $\mu$ and $\rho$, as shown in Equation (2) [34].

$$
\frac{d}{d t}(\rho \vec{v})+\nabla \cdot(\rho \vec{v} \vec{v})=-\nabla_{p}+\nabla \cdot\left[\mu\left(\nabla \vec{v}+\nabla \vec{v}^{T}\right)\right]+\rho \vec{g}+\vec{F}
$$

In the VOF model, the energy Equation (3), is shared among the phases [34].

$$
\frac{d}{d t}(\rho E)+\nabla \cdot(\vec{v}(\rho E+p))=\nabla \cdot\left(k_{e f f} \nabla T\right)+S_{h}
$$


Energy $E$ (Equation (4)) and temperature $T$ are treated as mass-averaged variables in the VOF model.

$$
E=\frac{\sum_{q=1}^{n} \alpha_{q} \rho_{q} E_{q}}{\sum_{q=1}^{n} \alpha_{q} \rho_{q}}
$$

where the specific heat of that phase and the shared temperature are what $E_{q}$ for each phase is based on [34]. The effective thermal conductivity $k_{e f f}$ and $\rho$ are shared by the phases. Influences from radiation and any other volumetric heat sources are what the source term $S_{h}$ comprises [34].

\subsection{Freeze Desalination Process Theory}

In order to simulate the freeze desalination process, energy (heat transfer), species transport and solidification/melting modules were used. Solidification/melting and species transport modules were utilised in order to separate the pure water (as ice) from the rejected brine solution [17]. Equations (5) to (17) describe the freeze desalination process on ANSYS Fluent and it is detailed by Jayakody et al. [7,17].

The material's enthalpy is calculated from Equation (5).

$$
H=h+\Delta H
$$

$h$ is the sensible enthalpy calculated by Equation (6).

$$
h=h_{r e f}+\int_{T_{r e f}}^{T} C_{p} d T
$$

The energy equation for solidification problems with the inclusion of species transport is shown in Equation (7) [17].

$$
\frac{d}{d t}(\rho H)+\nabla \cdot(\rho \vec{v} H)=\nabla \cdot(k \nabla T)+\frac{(1-\beta)^{2}}{\left(\beta^{2}+\varepsilon\right)} A_{m u s h} \vec{v}
$$

The liquid fraction, $\beta$ is found by Equation (8) [7].

$$
\beta=\frac{T-T_{\text {solidus }}}{T_{\text {liquidus }}-T_{\text {solidus }}} \text {, when } T_{\text {solidus }}<T<T_{\text {liquidus }}
$$

$\beta=0$, when $T<T_{\text {solidus }}$

$\beta=1$, when $T>T_{\text {liquidus }}$

The latent heat content is determined in terms of the latent heat of the material and the liquid volume fraction $\beta$ as shown in Equation (9). With values of $\beta$ ranging from 0 to 1 , this latent heat content can differ from 0 (solid) to $L$ (liquid).

$$
\Delta H=\beta L
$$

The apparent melting temperature is $T_{\text {melt }}$, where phase change occurs for solidification of a pure substance. A mushy freeze/melt region happens at a higher liquidus $\left(T_{\text {liquidus }}\right)$ temperature and a lower solidus temperature $\left(T_{\text {solidus }}\right)$ for a multicomponent mixture as shown in Equations (10) and (11) [35].

$$
\begin{gathered}
T_{\text {solidus }}=T_{\text {melt }}+\sum_{\text {solutes }} m_{i} Y_{i} / K_{i} \\
T_{\text {liquidus }}=T_{\text {melt }}+\sum_{\text {solutes }} m_{i} Y_{i}
\end{gathered}
$$


For species separation, the 'scheil' rule has been sourced at the micro-scale as it assumes no diffusion of solute species in the solid, and the species transport Equation (12) is determined as [7,36].

$$
\begin{gathered}
\frac{d}{d t}\left(\rho Y_{i, l i q}\right)+\nabla \cdot\left(\rho\left[\beta \vec{v}_{\text {liq }} Y_{i, l i q}+(1-\beta) Y_{i, s o l}\right]\right)=\nabla \cdot\left(\rho \beta D_{i, m, l i q} \nabla Y_{i, l i q}\right)- \\
K_{i} Y_{i, l i q} \frac{d}{d t}(\rho(1-\beta))+\frac{d}{d t}\left(\rho(1-\beta) Y_{i, l i q}\right)
\end{gathered}
$$

Equation (12) displays the mass fractions of liquid $Y_{i, l i q}$ and solid $Y_{i, \text { sol }}$, which are related by $K_{i}$, the partition coefficient [7].

$$
Y_{i, s o l}=K_{i} Y_{i, l i q}
$$

For the Scheil rule, $T^{*}$, the temperature at the interface is shown in Equation (14) [7].

$$
T^{*}=T_{\text {melt }}+\sum_{i=0}^{N_{s}-1} m_{i} Y_{i} \beta^{K_{i}-1}
$$

Thermal buoyancy occurs due to the variations in density with temperature and is determined by natural convection flows. Solutal buoyancy happens when density varies with species composition, and Equation (15) is used to calculate the solutal buoyancy body forces [17].

$$
\vec{F}_{s}=\rho_{r e f} \vec{g} \sum_{i=0}^{N_{s}} \beta_{s, i}\left(Y_{l, i}-Y_{r e f, i}\right)
$$

ANSYS Fluent uses a conservation equation of mass and momentum to solve for chemical species and the local mass fraction of each species and it is conducted by solving a convection-diffusion Equation (16) [17].

$$
\frac{d}{d t}\left(\rho Y_{i}\right)+\nabla \cdot\left(\rho \vec{v} Y_{i}\right)=-\nabla \cdot \vec{J}_{i}
$$

The momentum Equation (17) is solved between the phases and the subsequent velocity is shared [17].

$$
\frac{d}{d t}(\rho \vec{v})+\nabla \cdot(\rho \vec{v} \vec{v})=-\nabla p+\mu \nabla^{2} \vec{v}+\rho \vec{g}
$$

\section{CFD Methodology}

Computational fluid dynamics (CFD) was used to model the evaporation of liquid nitrogen to simultaneously conduct freeze desalination of saline water using the software ANSYS Fluent version 19.1 (ANSYS, Canonsburg, Pennsylvania, United States, 2018) [37].

\subsection{The Geometry}

The geometry has then been modelled using ANSYS geometry modeller of the CFD software, to the exact dimensions of the experimental test rig, which was designed based on results obtained for the cryogenic chill down process studied by Hartwig et al. [38].

Figure 1 shows the 3D geometry modelled using ANSYS geometry modeller consisting of two concentric tubes where the inner one is made of copper with an $8 \mathrm{~mm}$ diameter and it is surrounded by a Pyrex glass tube with a $28 \mathrm{~mm}$ diameter. The thickness of the copper tube and the glass tube were 0.5 and $3 \mathrm{~mm}$, respectively, with a total length of $1000 \mathrm{~mm}$. Liquid nitrogen flows through the inner tube, while the seawater stays stationary in the glass tube surrounding the copper tube. Only half of the geometry has been modelled due to the symmetrical nature of the pipes as shown in Figure 2, in order to reduce the computational time. 


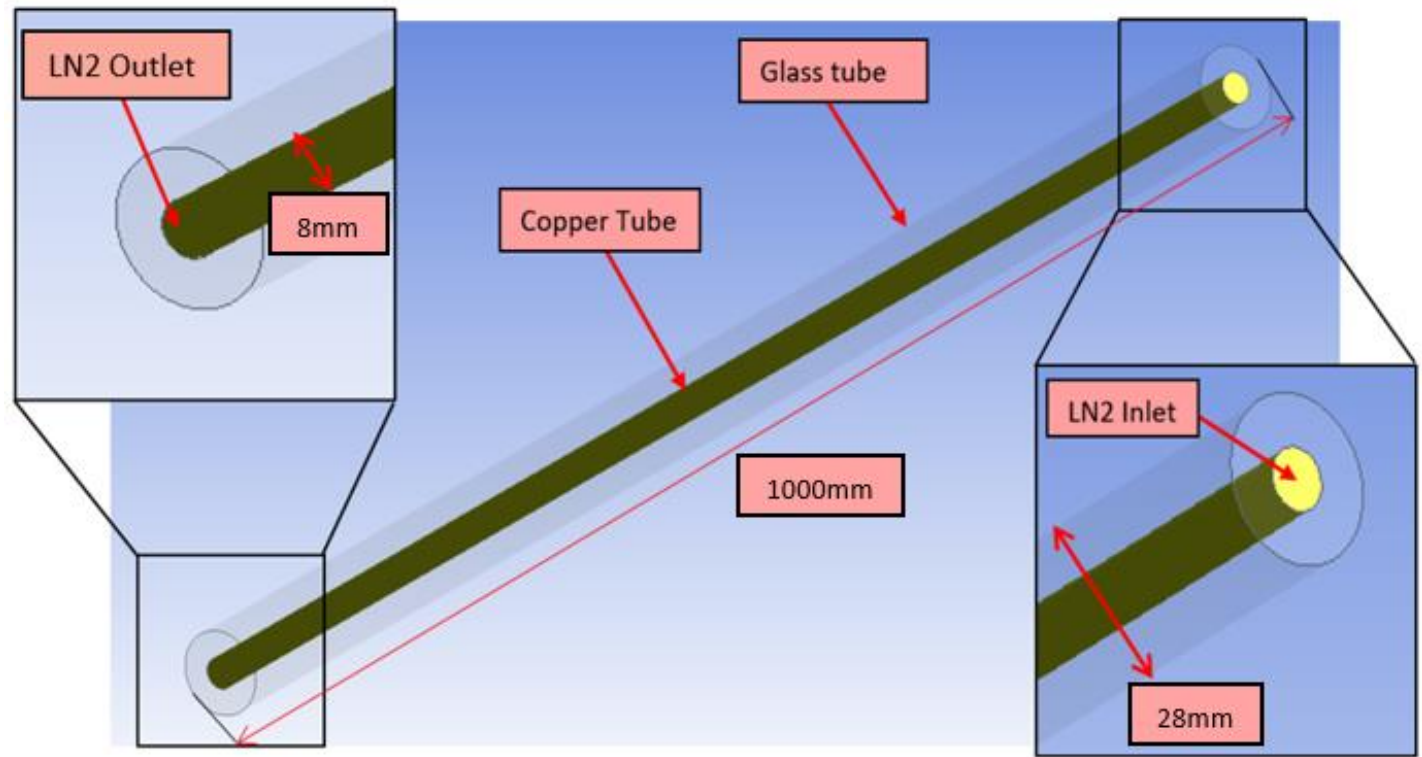

Figure 1. The geometry of the heat exchanger.

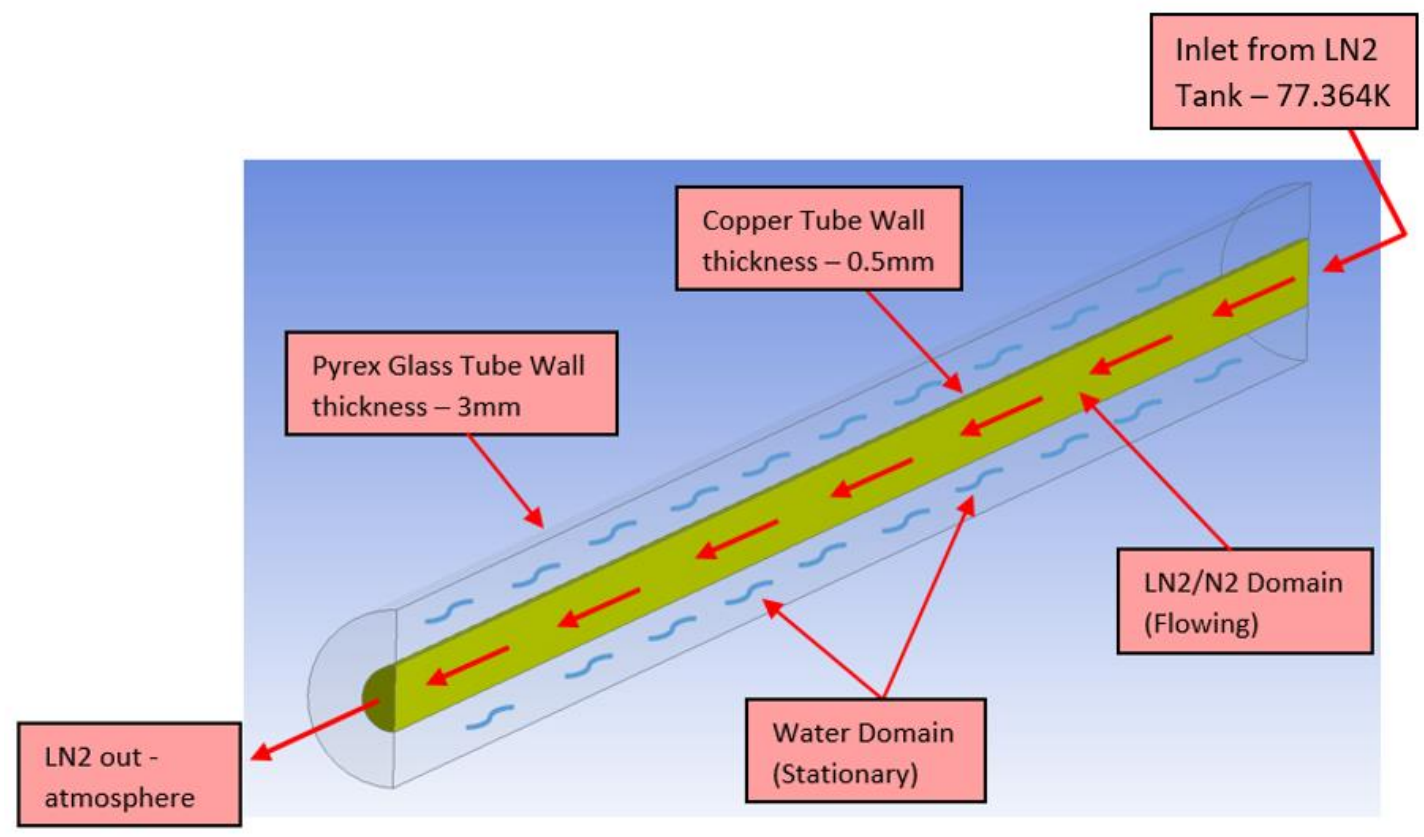

Figure 2. Heat exchanger domains and flow directions—cross-sectional view.

\subsection{The Mesh}

'ANSYS Meshing' (19.1, ANSYS, Canonsburg, Pennsylvania, United States, 2018) was used to create the $3 \mathrm{D}$ mesh of the geometry where a tetrahedral mesh has been created with edge sizing in order to optimise the mesh. Mesh independency study was conducted by using finer and coarser meshes with different edge sizing in order to select a suitable mesh as shown in Table 1. The predicted salinity of ice was compared with the measured salinity of ice $(0.9 \%)$, and the percentage errors are shown in Table 1. The quality of all the three meshes was good; however, increasing the density of the mesh requires longer computational time but produces more accurate results [7]. Further increase in the mesh density did not improve the results a great deal, thus a medium mesh has been chosen. 
Table 1. Mesh types used.

\begin{tabular}{|c|c|}
\hline Mesh Types & Description \\
\hline & $\begin{array}{l}\text { - Coarse mesh without edge sizing. } \\
\text { - Nodes: } 16750 \\
\text { - Elements: } 10461 \\
\text { - Salinity of ice (\%): } 0.65 \\
\text { - Percentage error (\%): } 27.8 \% \\
\text { - Total Running Time: } 2 \text { Days }\end{array}$ \\
\hline
\end{tabular}

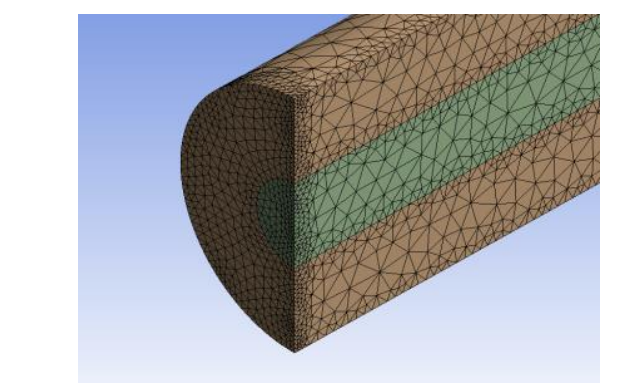

- Medium mesh with edge sizing.

- Nodes: 101081

- Elements: 64517

- Salinity of ice (\%): 0.73

- Percentage error (\%):18.9\%

- Total Running Time: 6 Days

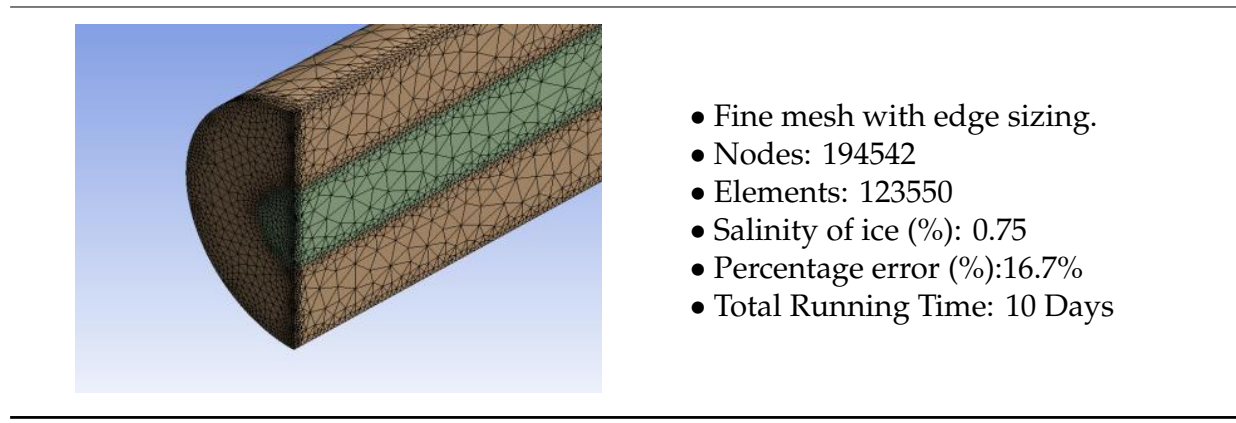

\subsection{Set-Up}

'ANSYS Fluent-Setup' (19.1, ANSYS, Canonsburg, Pennsylvania, United States, 2018) was used to define the solvers, materials, modules, boundary conditions, solution methods and discretization settings for the imported mesh. A transient solving process was selected due to time variation of the wall temperature during the cryogenic chill down process. A pressure-based solver was used with absolute velocity formulation enabled.

The boundary conditions are set to match the experimental test rig, and Figure 2 displays the labelled cross-sectional view of the CFD model. The system is divided into two sections where, the evaporation of liquid nitrogen domain is inside the copper tube while the surrounding glass tube contains the saltwater mixture domain to be frozen. Initially, the system is at ambient of $293.15 \mathrm{~K}$. Then, liquid nitrogen enters the tube at a temperature of $77.364 \mathrm{~K}$, evaporates inside the tube and leaves as nitrogen gas. The inlet is set as velocity inlet where the velocity of liquid nitrogen entering the system was $0.0006 \mathrm{~m} / \mathrm{s}$, and the outlet was set as a pressure outlet at atmospheric pressure. The surrounding salt solution is of $15 \mathrm{~g} / \mathrm{L}$ concentration $(1.5 \%)$ with an initial temperature of $293.15 \mathrm{~K}$. This salt solution is present inside the surrounding Pyrex glass tube where the copper tube makes contact with the salt solution to indirectly freeze and desalinate the solution.

In order to obtain the most accurate results in less computational time, a suitable time step must be selected by conducting time step size independency tests. Therefore, it is understood that increasing the time step size, decreased the computational time; however, decreasing the time step size improved the results' accuracy and avoided many errors in the ANSYS Fluent software. After conducting time 
step size independency tests by trial and error, a time step of $0.0001 \mathrm{~s}$ was used with 20 iterations per time step; thus, $5.4 \times 10^{6} \mathrm{~s}$ of time steps were required to run the simulation for $9 \mathrm{~min}$ real time. This was the optimum time step size that could be used, where increasing this time step size produced less accurate results, and decreasing this time step resulted in longer computational time. Increasing this time step also produced many errors such as 'floating point exception' to appear in the 'ANSYS Fluent Solution', resulting in the system crashing. With this time step size, it took about 6 days to complete one run with the mesh nodes and elements stated above in Table 1.

\section{CFD Results}

Figures 3-7 display the contours obtained after 9 min of real time. The temperature distribution of the liquid nitrogen in the copper tube in Figure 3 shows that $\mathrm{LN}_{2}$ travels from left to right, where only the beginning of the tube is at very low temperatures due to the very low velocity of $\mathrm{LN}_{2}$. The temperature distribution of the salt water surrounding the copper tube is shown in Figure 4.

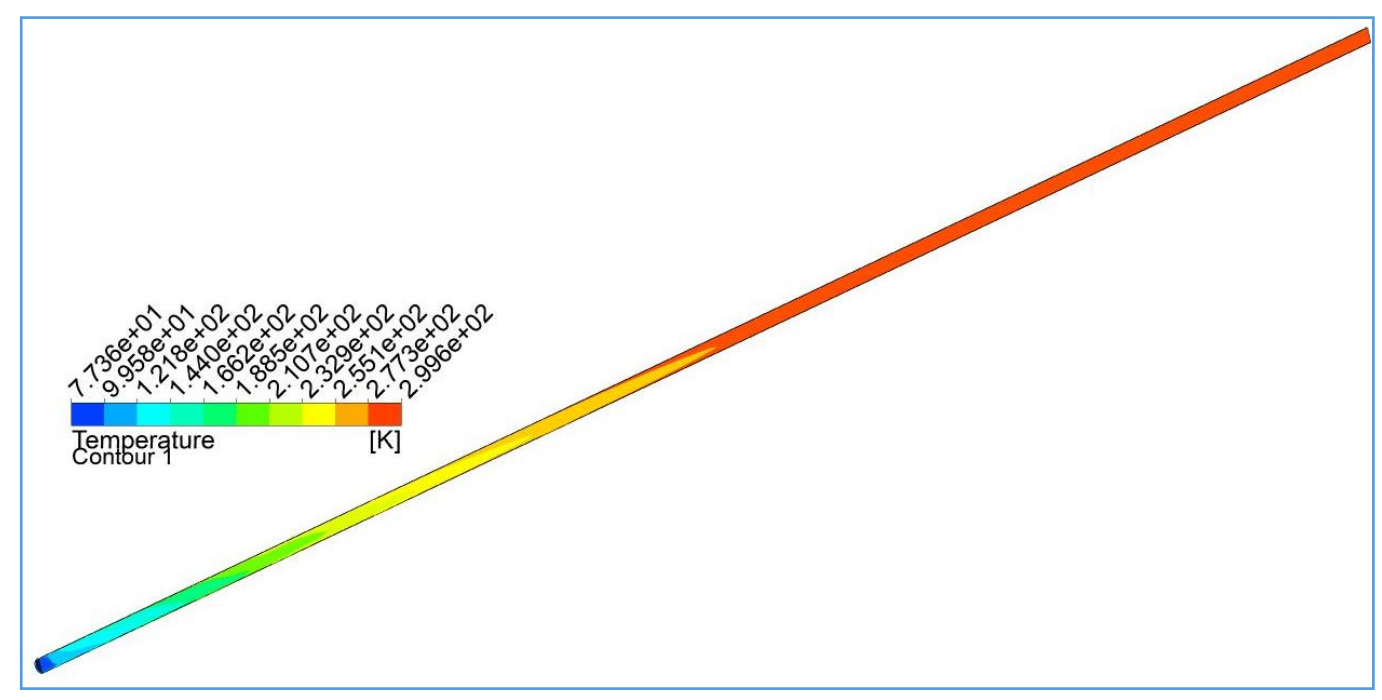

Figure 3. Temperature distribution of the $\mathrm{LN}_{2}$ copper tube.

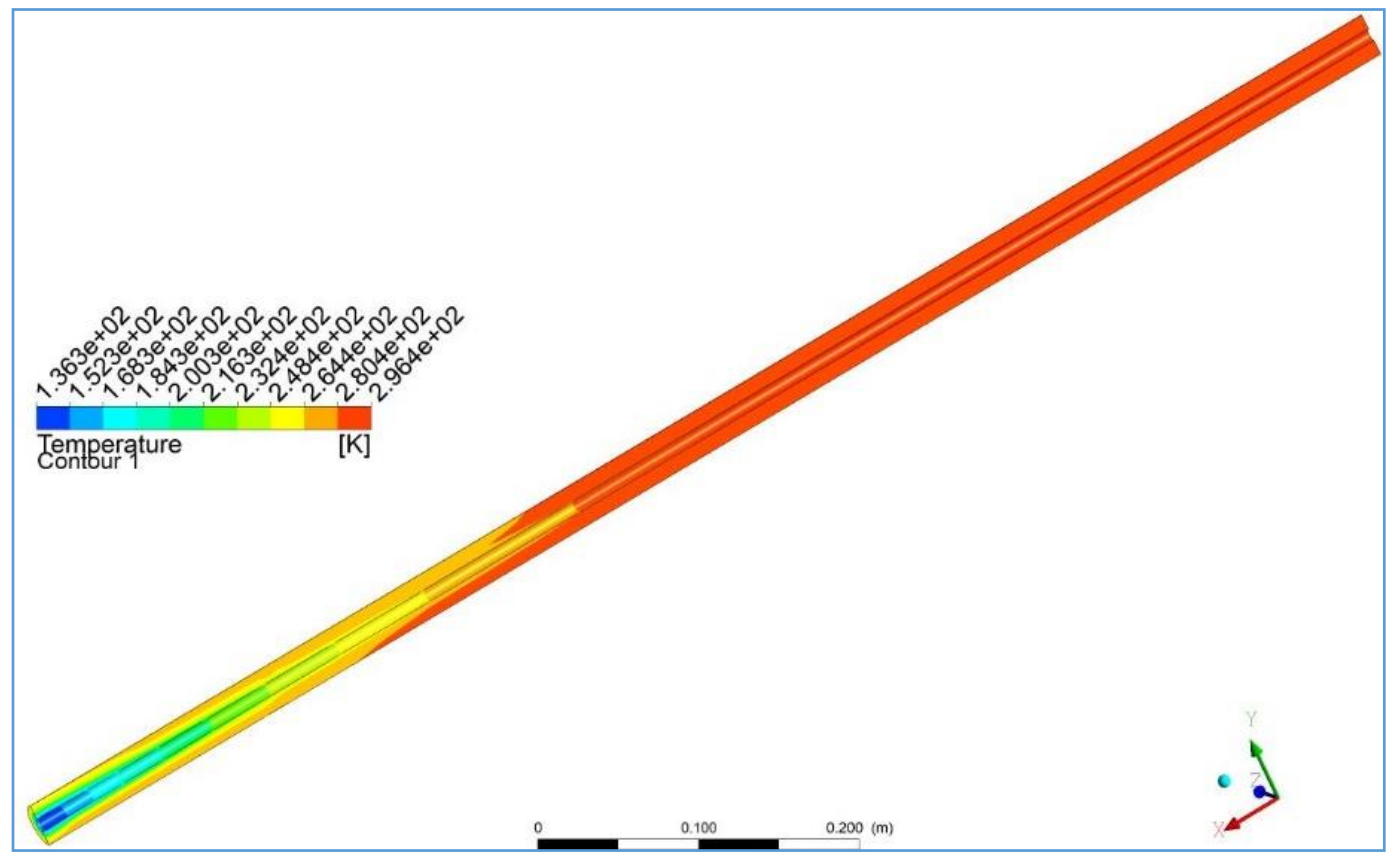

Figure 4. Temperature distribution of the salt water surrounding the copper tube. 


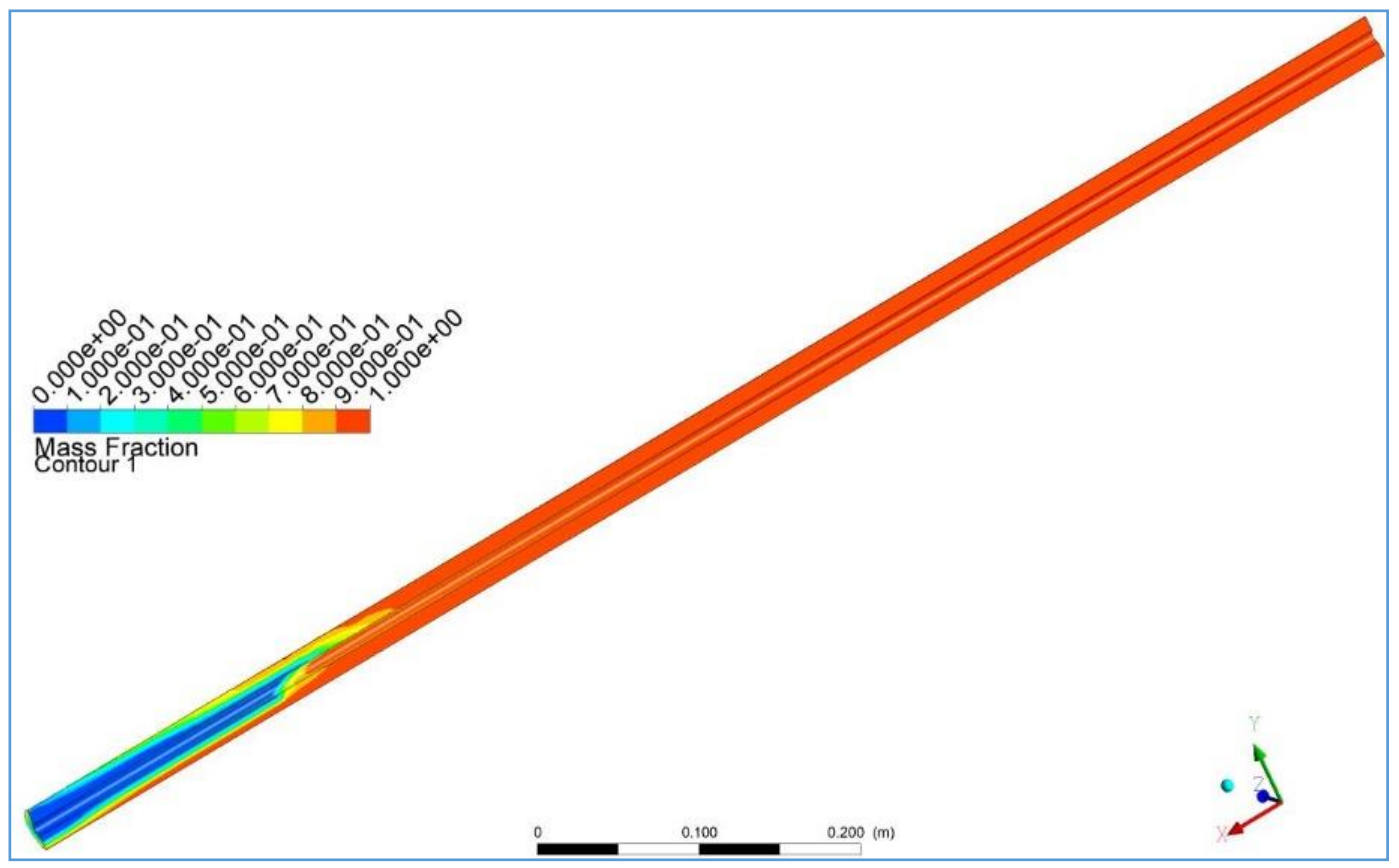

Figure 5. Liquid phase fraction contours.

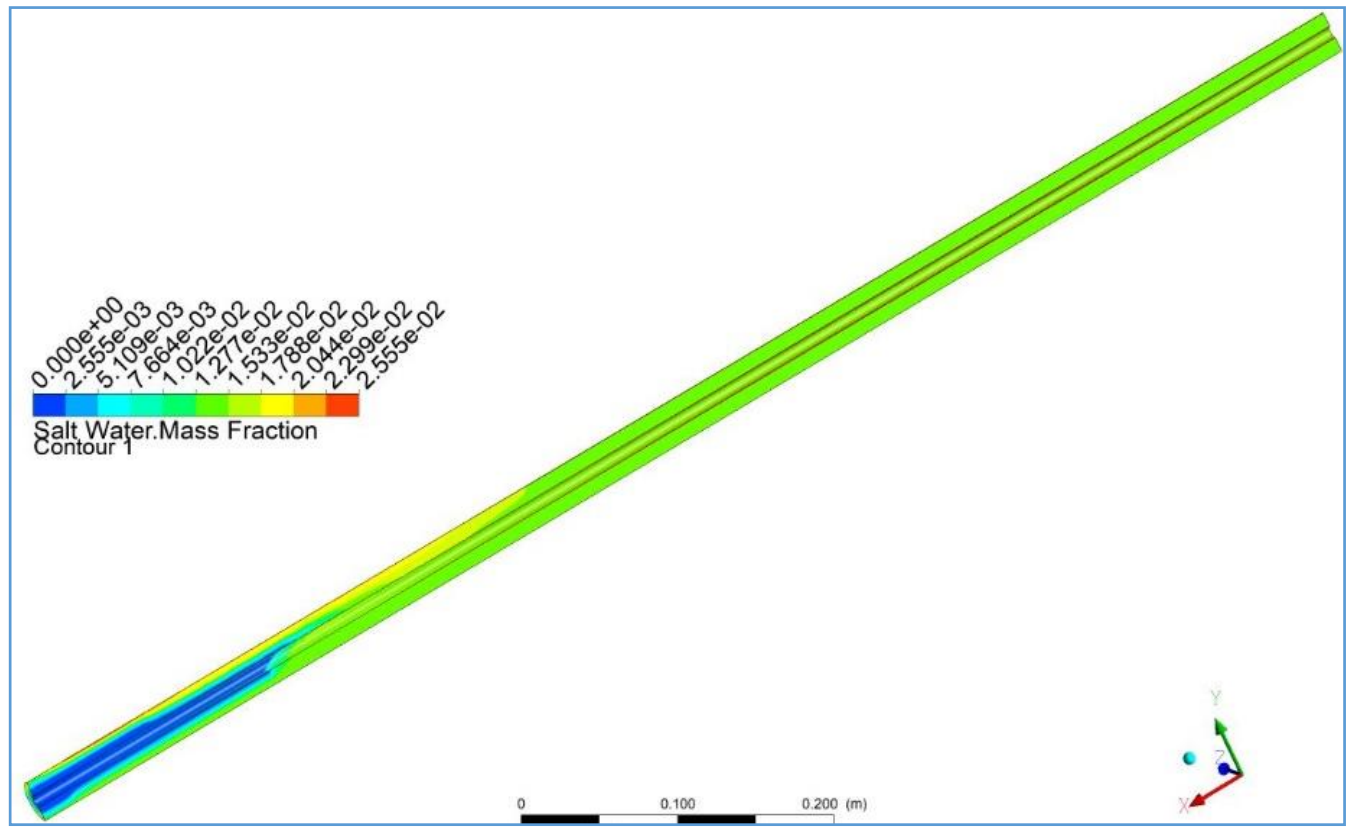

Figure 6. Salt water mass fraction contours.

Figure 5 displays the liquid phase fraction contours, where the formation of ice is shown. The blue region indicates the ice formed; the brine remaining is indicated by the red region, and the intermediate colours denote the liquid/solid mushy zone. Moreover, these contours go from 0 to 1 where 1 means it is pure liquid, 0 means it is pure solid, and the intermediate numbers represent the mushy regions. Liquid phase fraction contours in Figure 5 show that ice was formed only at the beginning of the tube due to the low velocity of $\mathrm{LN}_{2}$. The volume of ice formed was calculated by taking the blue region in Figure 5 and generating the volume in the software which is $46.71 \mathrm{~mL}$. 


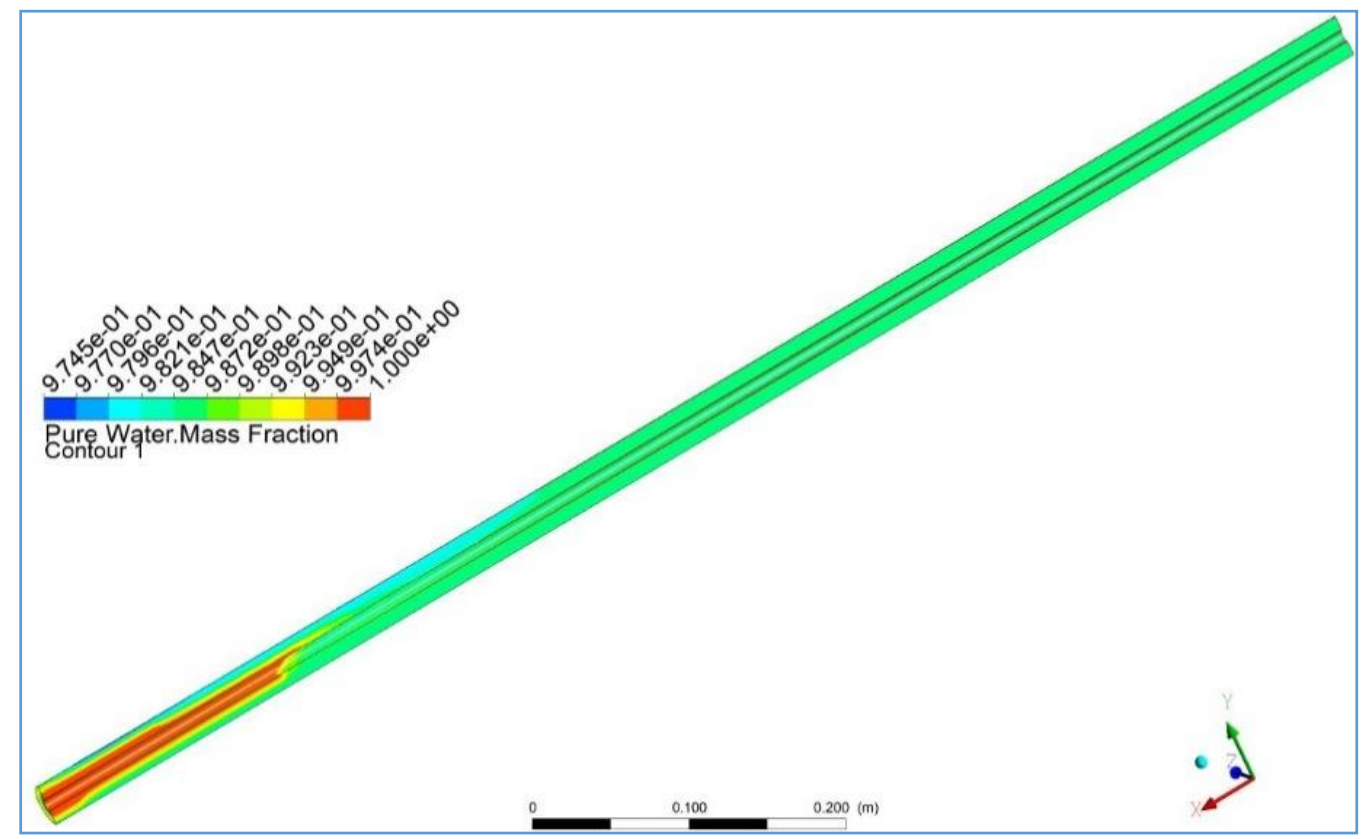

Figure 7. Pure water mass fraction contours.

Figures 6 and 7 show the salt water mass fraction and pure water mass fraction contours respectively. The salt water mass fraction is minimal in the regions where the ice is formed as shown in Figure 6, and the pure water mass fraction is very high in these regions as shown in Figure 7. The ice region generated from Figure 5 was used to calculate the salinity of ice, where the average salinity of the ice volume was calculated by the software. The volume remaining is the brine solution and its average salinity is calculated by the software. Hence, the salinity of ice formed was $0.73 \%$; the salinity of the remaining brine was $1.70 \%$, and it is calculated by taking the volume average over the whole domain.

\section{Experimental Test Facility}

This test rig was constructed to develop a system where the evaporation of liquid nitrogen would simultaneously desalinate seawater. The primary objective of this test rig was to understand the evaporation process of liquid nitrogen to be used for desalinating seawater. The heat transfer process was also examined where a method for enhancement of heat transfer was implemented in order to capitalize on the cold energy stored in liquid nitrogen.

The experimental test facility's schematic diagram is shown in Figure 8. This test rig is divided into two circuits, the evaporation of liquid nitrogen circuit and the freeze desalination one, which are connected by a heat exchanger. The concentric tube heat exchanger consists of a copper tube for the evaporation of $\mathrm{LN}_{2}$, which is surrounded by a glass tube that contains stationary seawater. A glass tube was chosen to store seawater in order to observe the formation of ice, and a copper tube was used for the $\mathrm{LN}_{2}$ evaporation process to ensure effective heat transfer between the evaporating nitrogen and the saline water.

In the first circuit, the liquid nitrogen was poured into an insulated $\mathrm{LN}_{2}$ tank, and it was circulated through an $8 \mathrm{~mm}$ diameter copper tube and into the atmosphere at moderately higher temperature. The $\mathrm{LN}_{2}$ flow rate was measured, and cryogenic thermocouples were placed at the inlet and outlet of the heat exchanger and as well as at different locations at the surface of the copper tube to measure the temperatures as shown in Figure 9. The pressure difference between the inlet and outlet was measured using a manometer. Insulation sheets and aluminium foil has been used to insulate the $\mathrm{LN}_{2}$ tank and the joining copper tubes. 


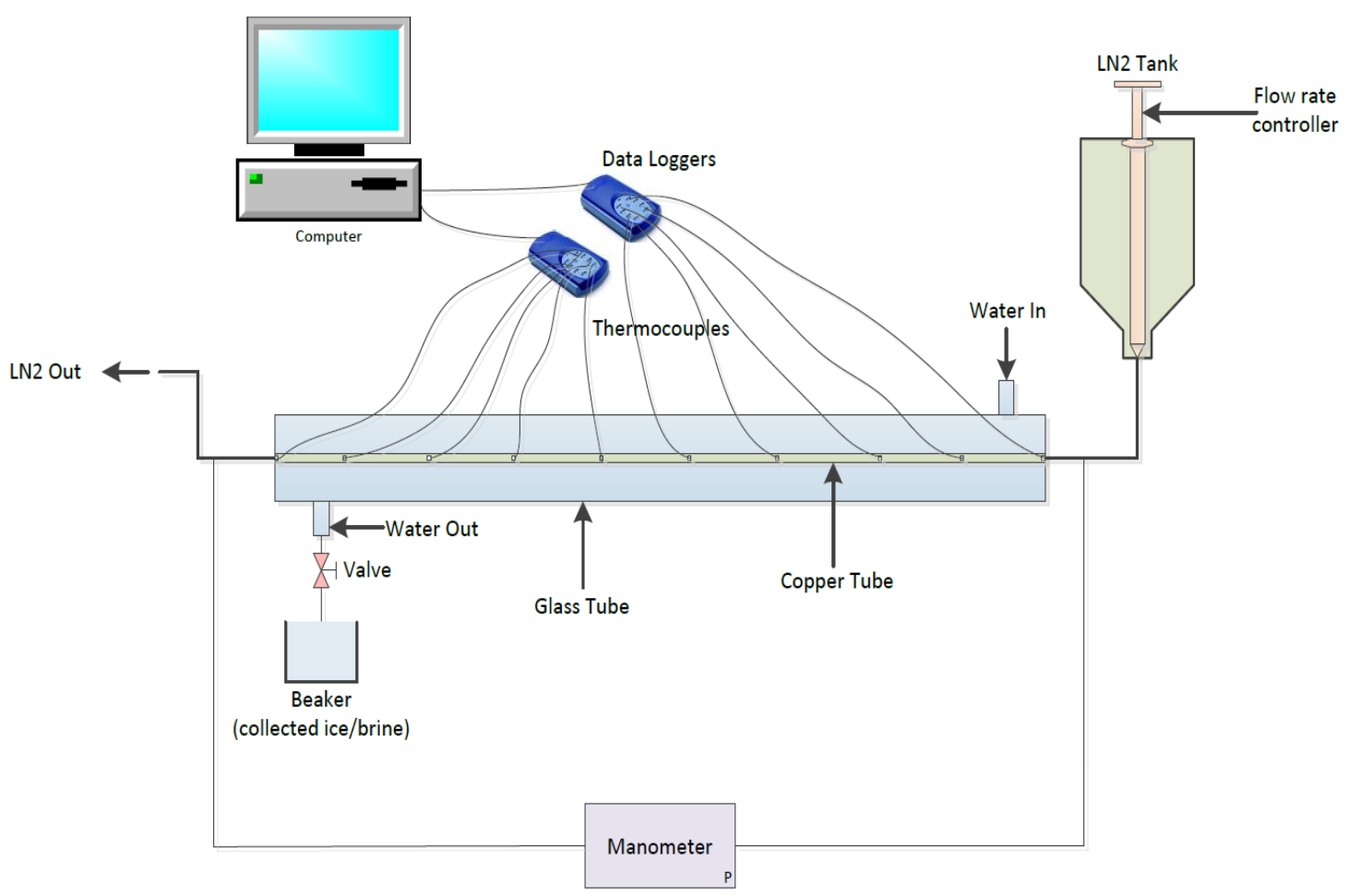

Figure 8. Schematic diagram of the experimental test facility.

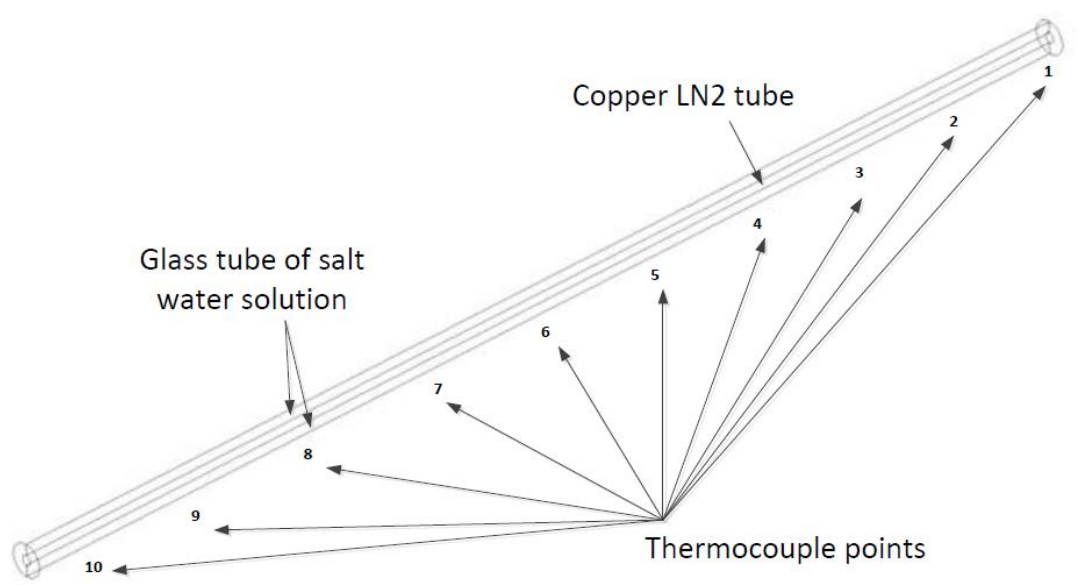

Figure 9. Schematic diagram showing the test rig with the thermocouple points.

In the second circuit, seawater of known salinity is poured into the glass tube which is surrounding the copper tube. This stationary seawater is cooled down by the evaporation of $\mathrm{LN}_{2}$. The temperature was measured at different locations at the surface of the copper tube using thermocouples. The temperature sensors were all connected to two data loggers that are connected to a computer to record the data. The complete test rig is shown photographically in Figure 10 with all its main components labelled. 


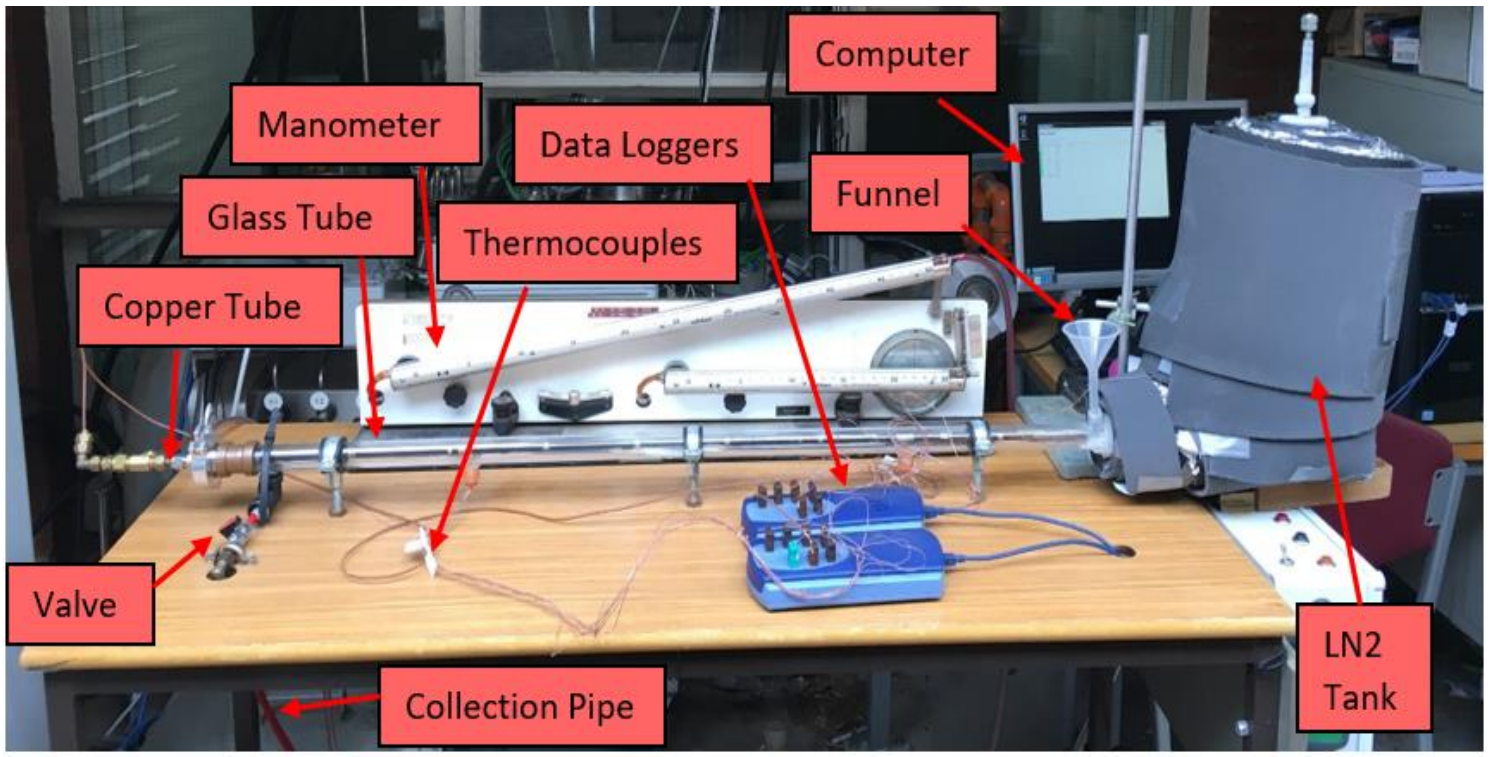

Figure 10. The developed test rig.

The overall length of this heat exchanger is $1000 \mathrm{~mm}$. The copper tube has an inner diameter of $8 \mathrm{~mm}$ with a $0.5 \mathrm{~mm}$ wall thickness, and the glass tube has an inner $28 \mathrm{~mm}$ diameter with a $3 \mathrm{~mm}$ wall thickness. The outer tube was made from glass that can handle cryogenic temperatures, and this allows the ice formation to be seen clearly as shown in Figure 10.

This test rig was built to study the evaporation of liquid nitrogen process for freeze desalination. In the first set of tests, the copper tube was kept as it was, and the flow rates were changed. In the second set of tests, a copper mesh was inserted into the copper tube in order to increase the transfer of heat and to improve the freezing rate. The inserted copper mesh had a wire diameter of $0.5 \mathrm{~mm}$ and is shown in Figure 11.

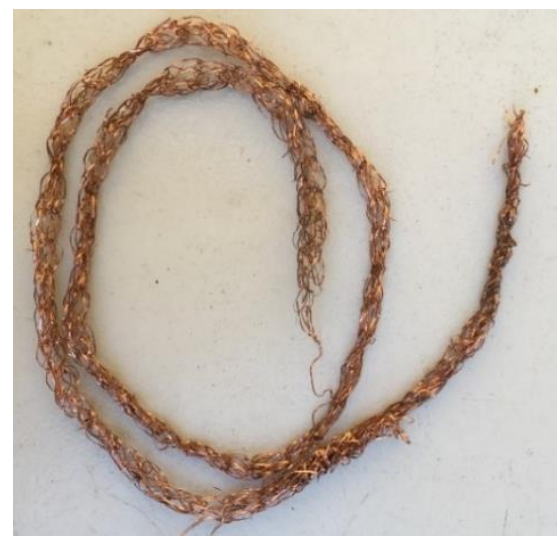

Figure 11. Copper Mesh.

The liquid nitrogen cryogenic tank is made of copper which has a total volume of $0.51 \mathrm{~L}$. The $54 \mathrm{~mm}$ diameter tank with a $207 \mathrm{~mm}$ length is connected to a reducer from 54 to $15 \mathrm{~mm}$ by a copper push fitting. This is then welded to another reducer to decrease the diameter to $8 \mathrm{~mm}$. In order to minimize heat transfer from the surrounding to the $\mathrm{LN}_{2}$ in the tank, 21 insulation sheets were wrapped around it. Moreover, aluminium foil was used between the insulation layers to reduce radiation heat transfer. A total of 21 layers of insulation sheets were selected as the temperature of the last insulation sheet was measured, and it was close to ambient temperature. These insulation sheets have a thermal conductivity of $0.035 \mathrm{~W} / \mathrm{m} . \mathrm{K}$ and of $3 \mathrm{~mm}$ thickness. Therefore, the total diameter with the insulation sheets converts to $230 \mathrm{~mm}$. Figure 12 shows the entire tank with its components. 


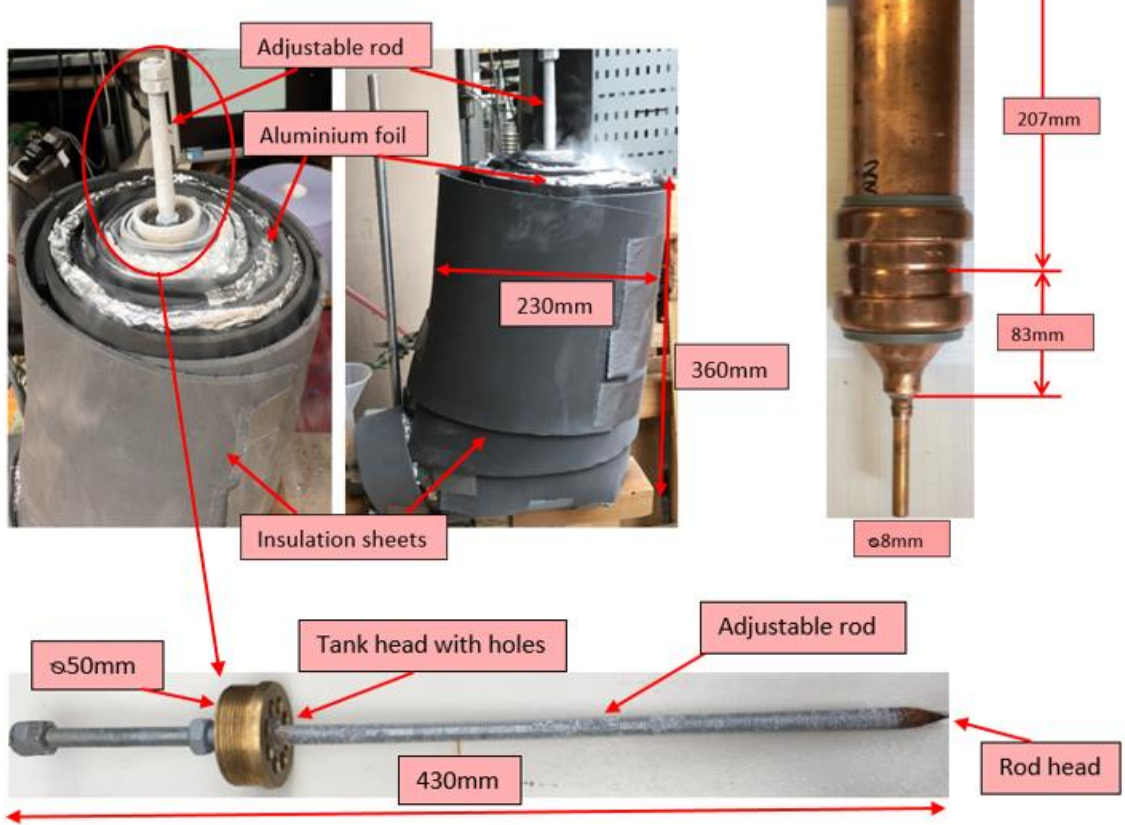

Figure 12. $\mathrm{LN}_{2}$ tank with its components.

The liquid nitrogen flow rate is controlled using an adjustable rod that is placed inside the tank as shown in Figure 12. The $430 \mathrm{~mm}$ rod works similar to a valve, where it is rotated to open and close at the rod head. The adjustable rod has several holes seen in Figure 12, and when it is inserted into the tank and placed at the tank head, it is used to prevent any build-up of pressure due to the evaporation of liquid nitrogen in the tank.

Thermocouples, salinity meter and a manometer were used in this experiment to measure temperatures, salinity and pressure difference respectively. In total, 12 calibrated thermocouples were used to measure the temperature at different locations in the test rig. Out of the 12, two of them were used to measure the temperature at the inlet and outlet of the liquid nitrogen copper tube. These two were thermocouple probes of type-K, which were used to measure the inlet temperature of $\mathrm{LN}_{2}$ and the outlet temperature of $\mathrm{N}_{2}$. The rest of the 10 thermocouples were cement-on surface thermocouples of type-K and were fitted at the outer surface of the copper tube to measure the temperature of the surface. These 10 thermocouples were equidistant from each other as shown in Figure 13, where T1 is closest to the $\mathrm{LN}_{2}$ inlet and T10 is closest to the $\mathrm{N}_{2}$ outlet.

\begin{tabular}{|llllllllllllll}
\hline LN2 & TUU & T10 & T9 & T8 & T7 & T6 & T5 & T4 & T3 & T2 & T1 & LN2 IN \\
\hline
\end{tabular}

Figure 13. Thermocouple distribution.

The pressure difference between inlet and outlet of the evaporation of liquid nitrogen was measured using an inclined differential manometer. In order to measure the salinity of the saline water, an Omega handheld salinity meter [39] was used. This has a range of $0.1 \%$ to $10 \%$ salinity and can operate at temperatures from -5 to $60{ }^{\circ} \mathrm{C}$ [39]. The salinity meter was used to measure the salinity of ice and brine after the freeze desalination process and also to measure the salinity when making saltwater solutions before the experiment. 


\section{Experimental Results}

\subsection{Effect of Test Conditions on Temperature and Energy}

Two tests were conducted, where the first test was conducted by evaporating $\mathrm{LN}_{2}$ in a smooth copper tube. In the second test, a copper mesh has been inserted in order to increase the heat transfer. The two tests were analysed in terms of the inlet and outlet temperatures of liquid nitrogen; the temperature of ice forming at the surface of the copper tubes and the volume and salinity for the ice and brine. In both tests, the initial saltwater salinity was $1.5 \%$, and three stages were conducted in order to desalinate the salt water to below $0.1 \%$, which is regarded as safe to drink by the WHO (World Health Organisation) [40]. The test matrix for the two tests carried out are shown in Table 2.

Table 2. Test matrix for experimental results.

\begin{tabular}{lcc}
\hline \multicolumn{1}{c}{ Test Parameters } & Test 1-without Mesh & Test 2-with Mesh \\
\hline $\mathrm{LN}_{2}$ mass flow rate (kg/s) & 0.000869 & 0.00055 \\
${\text { Inlet } \mathrm{LN}_{2} \text { temperature (K) }}$ - & 77.15 & 79.15 \\
Outlet $\mathrm{LN}_{2}$ temperature (K) & 199.15 & 276.5 \\
Initial saltwater temperature (K) & 291.15 & 291.15 \\
Final ice temperature (K) & 269.74 & 261.15 \\
Final brine temperature (K) & 283.8 & 278.47 \\
Average surface temperature of copper tube (K) & 275.14 & 273.55 \\
Pressure difference (Pa) & 255 & 950.16 \\
Initial saltwater salinity (\%) & 1.5 & 1.5 \\
First stage ice salinity (\%) & 0.9 & 0.9 \\
Second stage ice salinity (\%) & 0.4 & 0.4 \\
Third stage ice salinity (\%) & 0.1 & 0.1 \\
Total energy lost by water (kJ) & 31.81 & 102.65 \\
Total energy in LN $(\mathrm{kJ})$ & 149.41 & 149.41 \\
Percentage of energy lost by water from $\mathrm{LN}_{2}$ to & 21.42 & 69.61 \\
form ice (\%) & 21 & 85 \\
Heat exchanger effectiveness (\%) & & \\
\hline
\end{tabular}

In the first test, liquid nitrogen passed through the copper tube and evaporated at a flow rate of $8.69 \times 10^{-4} \mathrm{~kg} / \mathrm{s}$, simultaneously freezing the saline water surrounding the copper tube. Figure 14 shows the temperature distribution of liquid nitrogen at inlet and outlet and the initial and final water temperatures. The inlet temperature of $\mathrm{LN}_{2}$ was $77.15 \mathrm{~K}$, and the outlet temperature was $199.15 \mathrm{~K}$ indicating that energy has been lost by water for ice formation, and a considerable amount of energy has been lost to the surroundings. The initial temperature of salt water was $291.15 \mathrm{~K}$, and the average temperatures for ice formed and brine remaining were $269.74 \mathrm{~K}$ and $283.8 \mathrm{~K}$, respectively.

The surface temperatures at the copper tube surface T1 to T10 were monitored and are displayed in Figure 15. It is seen in this figure that the temperature increases from T1, which is closest to the $\mathrm{LN}_{2}$ inlet to $\mathrm{T} 10$, which is closest to the $\mathrm{LN}_{2}$ outlet. The decrease in temperature causes the water to freeze and to form ice. Hence, it is clear that ice is only formed at locations T1 to T3 where the surface temperature is below $273.15 \mathrm{~K}$. This ice is of low salinity compared to the rest of the remaining brine solution. The mean temperature at the tube surface was calculated to be $275.14 \mathrm{~K}$. The pressure difference was also monitored using the manometer to be $255 \mathrm{~Pa}$. 


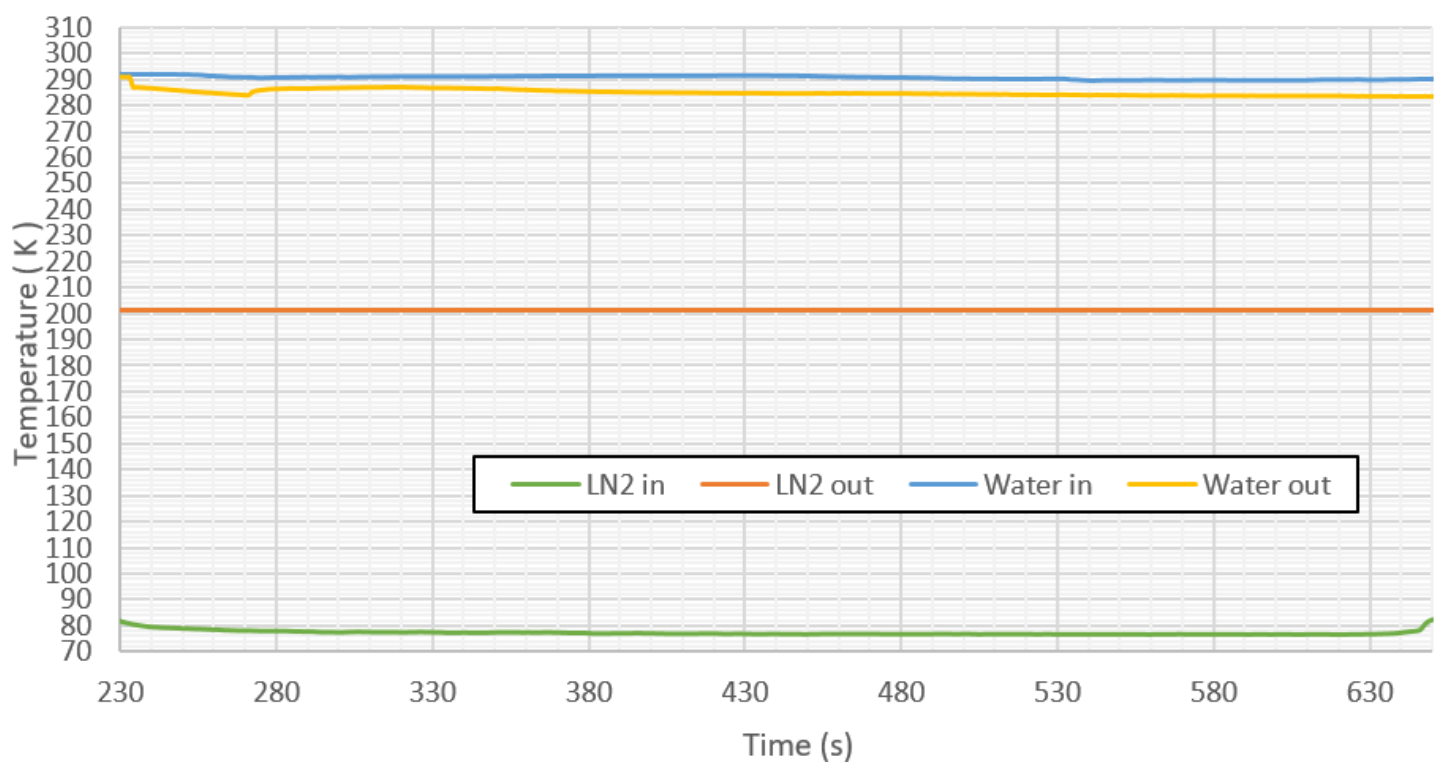

Figure 14. Test $1-\mathrm{LN}_{2}$ and water temperature distribution.

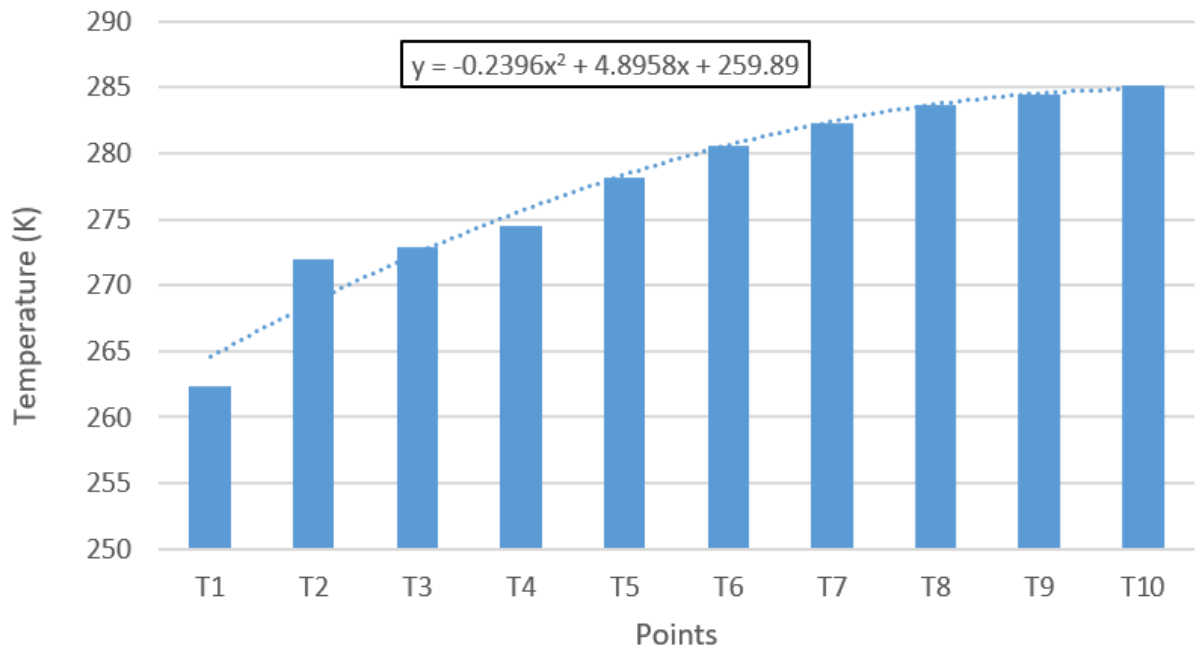

Figure 15. Test $1-$ Temperature at copper tube surface T1-T10.

The total energy lost by water was calculated using Equation (18), consisting of four terms: firstly, the energy lost from the remaining brine; secondly, the energy lost from water when ice was formed which was calculated from the initial conditions to the freezing point (F.P) of salt water; thirdly, the energy gained by ice which was calculated from the freezing point (F.P) of salt water to the final temperature of ice; and finally, the latent heat of fusion.

$$
Q_{\text {total water }}=Q_{\text {brine }}+Q_{\text {water to F.P }}+Q_{F . P \text { to ice }}+m L_{f}
$$

where $L_{f}$ is the latent heat of fusion for seawater and $m$ is the mass. Equation (19) was used to find the energy for ice, water and brine.

$$
\mathrm{Q}_{\text {ice } / \text { water } / \text { brine }}=m\left(\mathrm{Cp}_{2} \mathrm{~T}_{2}-\mathrm{Cp}_{1} \mathrm{~T}_{1}\right)
$$

where $C \mathrm{p}_{1}$ and $C \mathrm{p}_{2}$ are the initial and final specific heat capacities of water respectively. $T_{1}$ and $T_{2}$ are the initial and final temperatures respectively. 
The energy balance for the hot stream of saline water and the cold stream of $L N_{2}$ passing through the heat exchanger was evaluated. The total energy lost by salt water to form ice was calculated using Equations (18) and (19).

In order to find the percentage of energy lost by water to form ice from liquid nitrogen, first the energy in liquid nitrogen is calculated using Equation (20).

$$
\mathrm{E}_{L N 2}=\text { Energy Density of } L N_{2} \times \text { Volume of } L N_{2}
$$

The energy density of $L N_{2}$ was calculated using $H_{1}$ and $H_{2}$, which are the inlet and outlet enthalpies obtained from thermodynamic property tables for nitrogen [41]. The volume of $L N_{2}$ used depended on how many freezing stages were carried out.

Then, the percentage of energy lost by water to form ice (overall efficiency) from liquid nitrogen was calculated using Equation (21).

$$
\% \text { of Cold Energy Recovered }=\frac{Q_{\text {total water }}}{E_{L N 2}} \times 100
$$

where $Q_{\text {total water }}$ is the total energy lost by water calculated using Equations (18) and (19).

The energy calculations were calculated using Equations (18) to (21), and they are summarised in Table 3. It can be seen that only $21.42 \%$ of energy was absorbed in order to form ice in the first test.

Table 3. Test 1-Energy calculations.

\begin{tabular}{cc}
\hline Total energy lost by water $(\mathrm{kJ})$ & 31.81 \\
Total energy in $\mathrm{LN}_{2}(\mathrm{~kJ})$ & 149.41 \\
Percentage of energy lost by water from $\mathrm{LN}_{2}$ to form ice $(\%)$ & 21.42 \\
Heat exchanger effectiveness $(\%)$ & 21 \\
\hline
\end{tabular}

The heat exchanger effectiveness has been calculated using Equations (22) to (28). When designing a heat exchanger, the two primary approaches are the Log Mean Temperature Difference (LMTD) method and the effectiveness Number of Thermal Units (NTU) method. The heat exchanger effectiveness was calculated as follows. Firstly, the LMTD was calculated using Equation (22).

$$
\Delta \mathrm{T}_{\mathrm{LMTD}}=\frac{\Delta \mathrm{T}_{2}-\Delta \mathrm{T}_{1}}{\ln \frac{\Delta \mathrm{T}_{2}}{\Delta \mathrm{T}_{1}}}
$$

where $\Delta \mathrm{T}_{1}$ and $\Delta \mathrm{T}_{2}$ are the difference in temperatures at the ends of the heat exchanger and are calculated by Equations (23) and (24).

$$
\begin{aligned}
& \Delta T_{1}=\mathrm{T}_{\mathrm{W} 1}-\mathrm{T}_{\mathrm{N} 1} \\
& \Delta \mathrm{T}_{2}=\mathrm{T}_{\mathrm{W} 2}-\mathrm{T}_{\mathrm{N} 2}
\end{aligned}
$$

$\mathrm{T}_{\mathrm{W} 1}$ and $\mathrm{T}_{\mathrm{W} 2}$ are the water inlet and outlet temperatures and $\mathrm{T}_{\mathrm{N} 1}$ and $\mathrm{T}_{\mathrm{N} 2}$ are the nitrogen inlet and outlet temperatures.

In order to calculate the effectiveness, the NTU, was calculated using Equation (25).

$$
\mathrm{NTU}=\frac{\mathrm{UA}}{\mathrm{C}_{\min }}
$$

$\mathrm{C}_{\min }$ is the smaller heat capacity, and it is calculated by Equation (26). A is the surface area of the copper tube, and $\mathrm{U}$ is the overall heat transfer coefficient calculated by Equation (27).

$$
\mathrm{C}_{\min }=\dot{\mathrm{mC}_{\mathrm{p}}}
$$




$$
\mathrm{U}=\frac{\dot{\mathrm{Q}}}{\mathrm{A} \Delta \mathrm{T}_{\mathrm{LMTD}}}
$$

When phase change evaporation occurs in the heat exchanger, then the behaviour of the heat exchanger is independent of flow arrangement. Therefore, the effectiveness of the heat exchanger is calculated using Equation (28).

$$
\varepsilon=1-e^{-N T U}
$$

The heat exchanger effectiveness for the test without the mesh was very low, and it was only $21 \%$ as shown in Table 3.

In the second test, a copper mesh (Figure 11) was inserted halfway through the copper tube in order to increase the heat transfer between the fluids, and these two tests varied due to different flow rates of $\mathrm{LN}_{2}$. The mesh was only inserted at the halfway point of the tube due to the fact that there is a considerable amount of freezing seen at the beginning of the tube where the liquid nitrogen is entering; therefore, adding a mesh here would mean that there would be an uncontrollable amount of freezing, causing the surrounding glass tube to crack at the beginning of the tube.

In the second test, the $\mathrm{LN}_{2}$ flow rate was $5.55 \times 10^{-4} \mathrm{~kg} / \mathrm{s}$ and the water remained stationary. The $\mathrm{LN}_{2}$ inlet and outlet temperatures were 79.15 and $276.5 \mathrm{~K}$, respectively, as shown in Figure 16. The initial temperature of saline water was $291.15 \mathrm{~K}$, and the produced ice had a temperature of $261.15 \mathrm{~K}$ and the remaining brine a temperature of $278.47 \mathrm{~K}$.

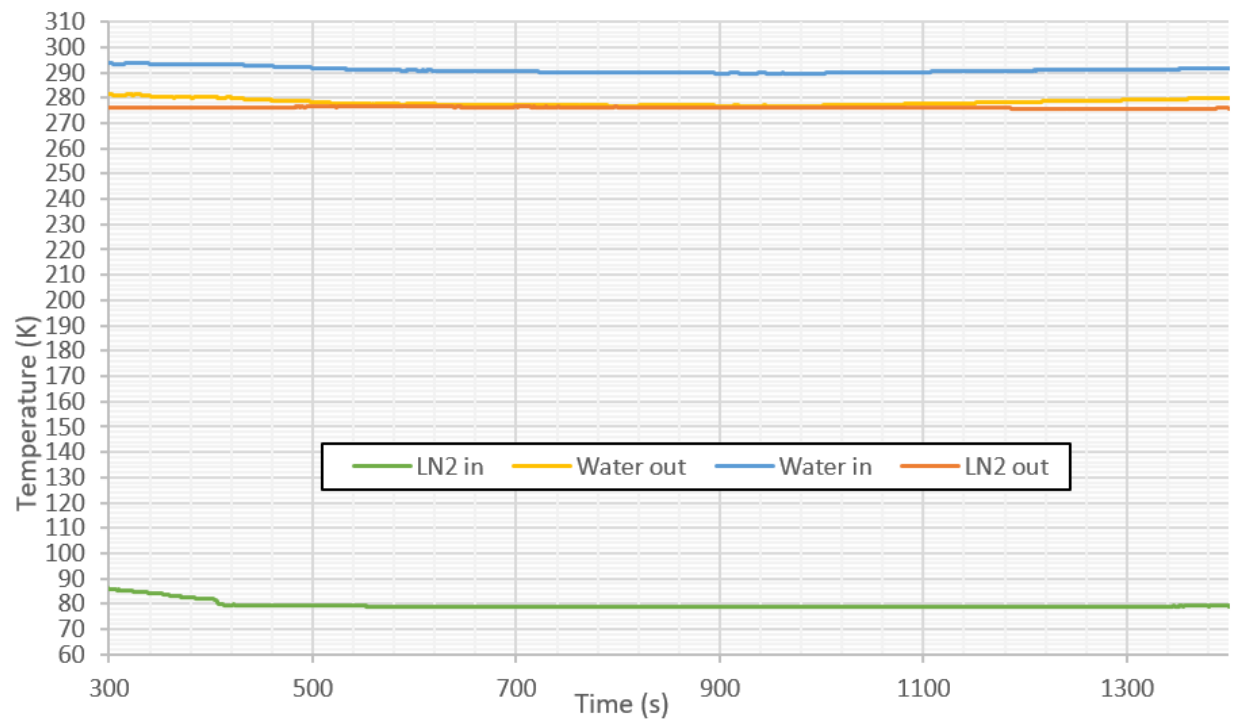

Figure 16. Test 2- $\mathrm{LN}_{2}$ and water temperature distribution.

The mean temperature at the surface walls was calculated to be $273.55 \mathrm{~K}$. The temperature distribution is very different to the first test as shown in Figure 17. This can be explained as follows; since the copper mesh was inserted up to the halfway point of the tube, a considerable amount of heat transfer is seen at the beginning of the mesh, leading to low temperature, at points T5-T8.

The pressure difference was $950.16 \mathrm{~Pa}$ and $69.61 \%$ of the cold energy was absorbed by water from $\mathrm{LN}_{2}$. The heat exchanger effectiveness was also much higher for the test with the mesh inserted as it is $85 \%$, which is 4 times more than the first test without the mesh as shown in Table 4 . 


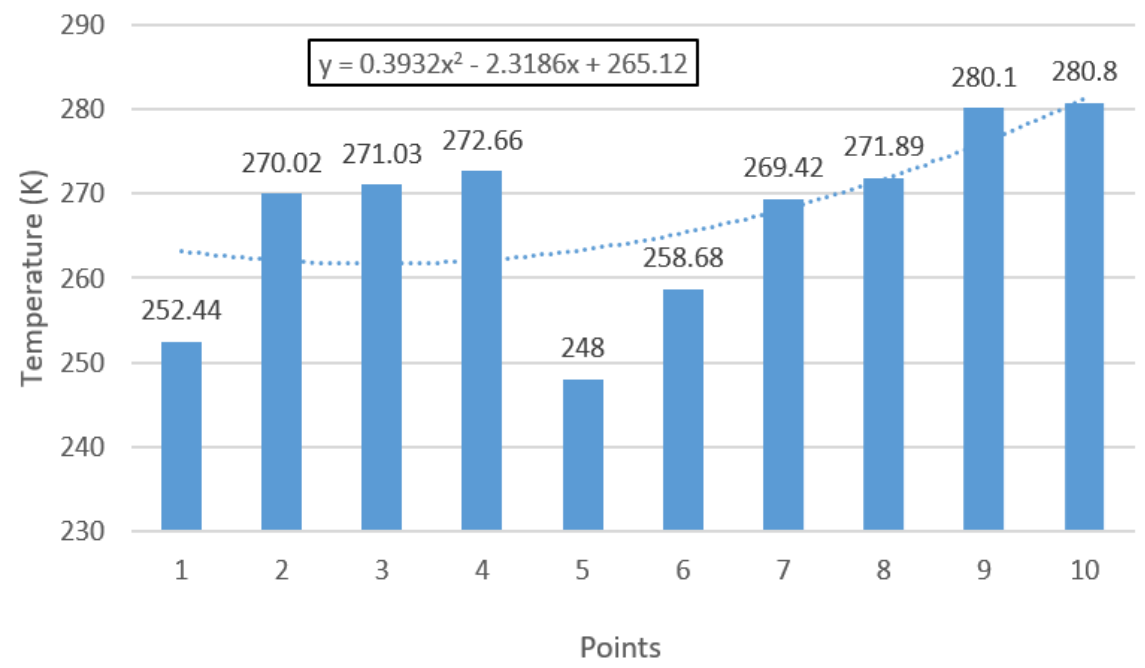

Figure 17. Test 2-Temperature at copper tube surface T1-T10.

Table 4. Test 2-Energy calculations.

\begin{tabular}{cc}
\hline Total energy lost by water $(\mathrm{kJ})$ & 102.65 \\
Total energy in $\mathrm{LN}_{2}(\mathrm{~kJ})$ & 149.41 \\
Percentage of energy lost by water from $\mathrm{LN}_{2}$ to form ice $(\%)$ & 69.61 \\
Heat exchanger effectiveness $(\%)$ & 85 \\
\hline
\end{tabular}

The first test had a higher liquid nitrogen flow rate due to the absence of the copper mesh and resulted in most of the energy being wasted into the atmosphere as the nitrogen leaves at low temperature with trapped liquid droplets. The copper mesh enhanced the heat transfer rate at a great deal resulting in more ice production. The percentage of energy lost by water from $\mathrm{LN}_{2}$ to form ice is shown in Tables 2 and 3, where it is seen that the mesh improved the percentage of energy lost by water significantly. The heat exchanger effectiveness values for the two tests conducted with and without the mesh are shown in Tables 2 and 3. It is seen that the energy loss is greater in the test conducted without the mesh. The test with a mesh being inserted showed greater effectiveness and less energy loss.

\subsection{Effect of Test Conditions on Salinity and Volume of Ice}

A salt solution of $1.5 \%$ salinity was indirectly freeze desalinated by the evaporation of liquid nitrogen. Three stages of freezing were conducted in order to bring $1.5 \%$ salt water salinity to $0.1 \%$, which is recommended as safe to drink by the WHO [40]. In order to obtain accurate results by undergoing repeatability, three experiments were conducted of the same initial conditions, where $1.5 \%$ salinity was desalinated in three stages as shown in Figure 18 . The salinity dropped to $0.9 \%$ in the first stage and then after freezing the $0.9 \%$ salinity solution in the second stage, it dropped to $0.4 \%$. The $0.4 \%$ solution was then taken to conduct freezing in the final stage and it dropped to $0.1 \%$, which is within the acceptable limits of safe to drink water by the WHO [42].

Figure 19 shows the volume of ice obtained at each freezing stage for the experiment conducted with a mesh being inserted. Therefore, it is seen that in the first stage, the volume of ice obtained is low, and it increases as the salinity of the initial salt solution decreases. Jayakody et al. [7] explained that the ice crystals become less pure at higher initial salt water concentrations. William et al. [43] proved that the initial salt water salinity had a significant effect on salt rejection and water recovery ratios. 


\section{Different stages of freezing}

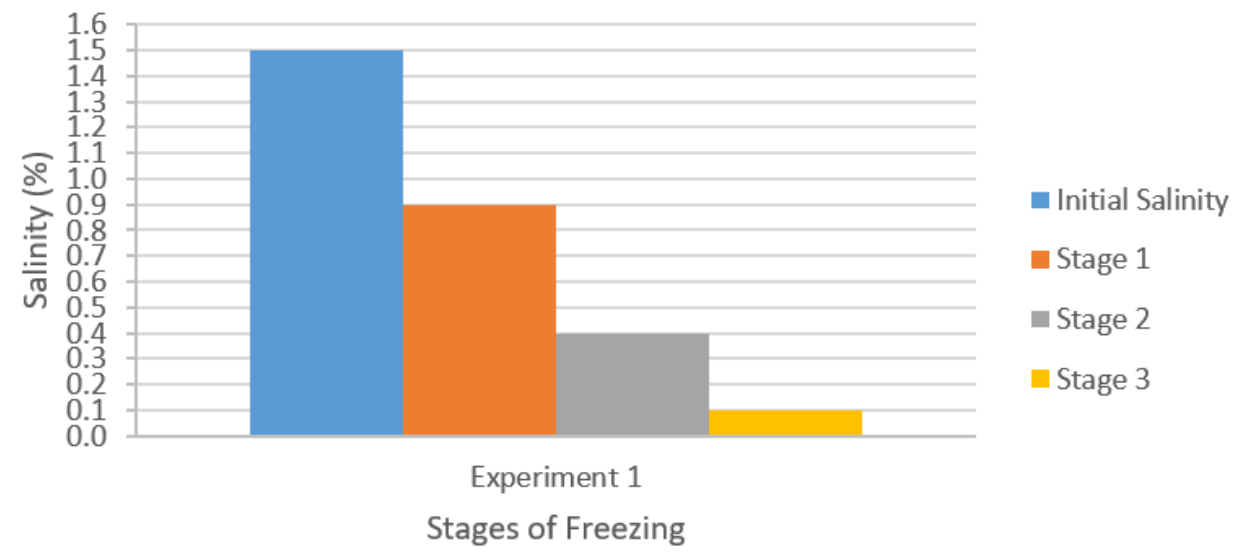

Figure 18. Three experiments conducted in three freezing stages.

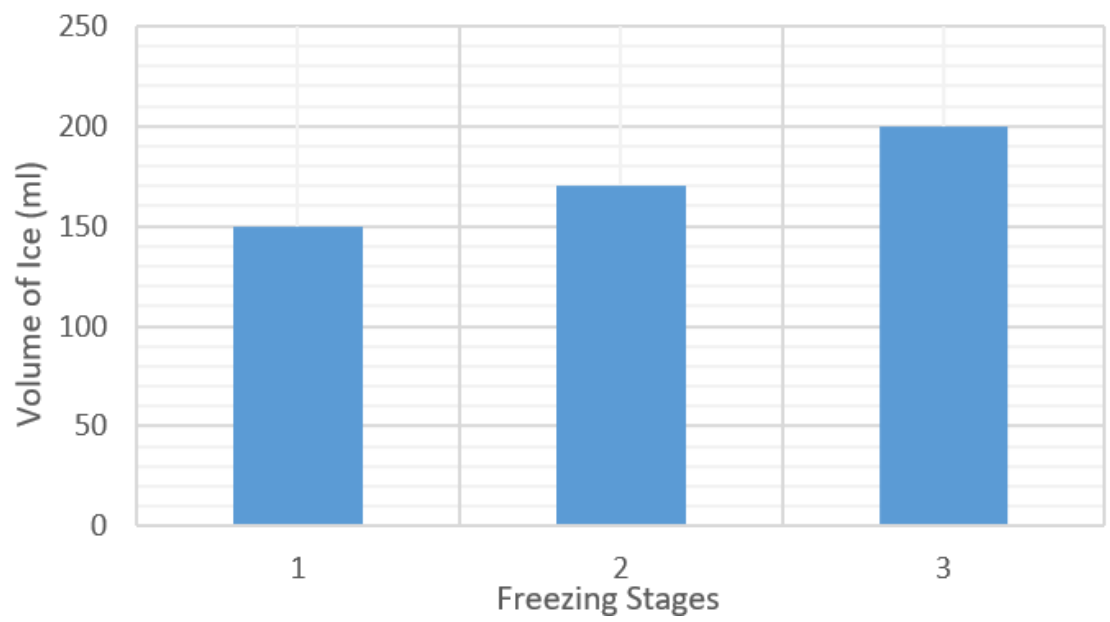

Figure 19. Volume of ice for different freezing stages on average for the 3 experiments conducted for the tests done with the mesh.

\section{CFD Modelling Validation}

The CFD model was validated using experimental work, where the operating conditions of the experiment were inputted in the CFD model as boundary conditions. The validation process was only carried out to a test done without the mesh as including a mesh inside the copper tube would require an excessively large computational time on CFD. The validation process was carried out in terms of the temperatures at the outer surface of the copper tube, volume of ice formed and also the ice and brine salinities.

Figure 20 compared the CFD predicted temperatures to their corresponding measured values at various locations on the copper tube surface at $9 \mathrm{~min}$ of real time. In this figure, the experimental (a test carried out with a mass flowrate of $7.45 \times 10^{-4} \mathrm{~kg} / \mathrm{s}$ ) temperature from T1-T10 were compared with those predicted by CFD, showing good agreement. The deviation from the experimental values was minimal with maximum deviations at T3 and T9 of 9.9 and $9.2 \mathrm{~K}$, respectively. Additionally, the average deviation of all the points was $6.3 \mathrm{~K}$. The average wall temperature of the experimental work was $277.75 \mathrm{~K}$ and that of the CFD was $275.25 \mathrm{~K}$ indicating good agreement. 


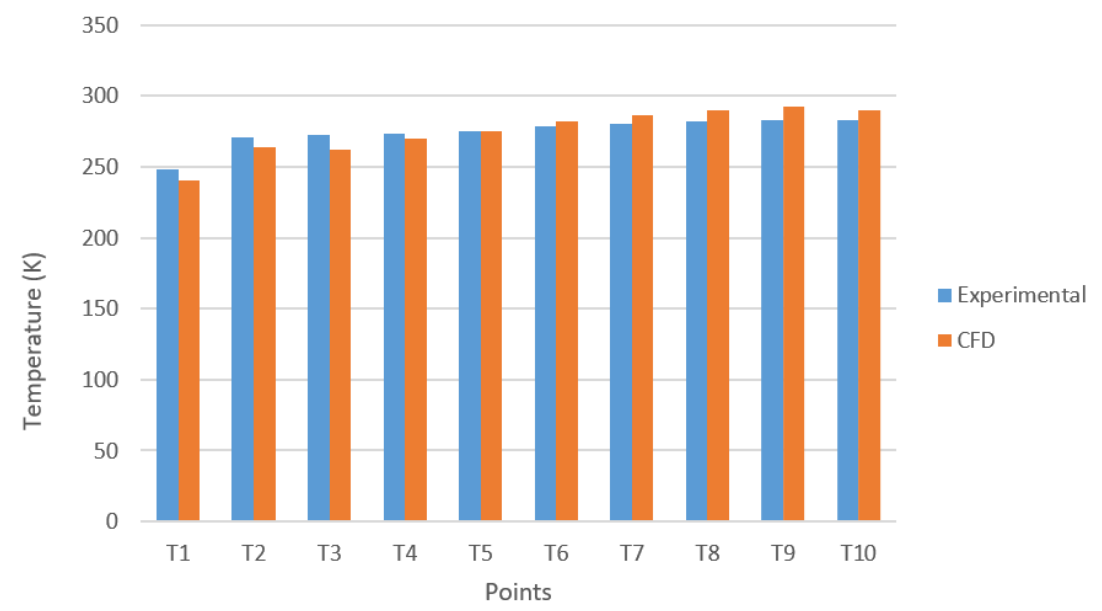

Figure 20. Temperature comparison at different locations of the copper tube.

The CFD predicted volume of ice formed, and the ice and brine salinities were compared to the experimental values for each stage of freezing as shown in Table 5. It is apparent that the ice and brine salinities and the volumes of ice formed at each stage of freezing show good agreement.

Table 5. Salinity and volume for each stage of freezing for CFD and experimental without mesh.

\begin{tabular}{cccccccccc}
\hline & \multicolumn{9}{c}{ Initial Salinity of Seawater (\%) at Each Stage of Freezing } \\
\cline { 2 - 10 } Parameters & \multicolumn{2}{c}{ Stage } & $\mathbf{1 - 1 . 5 \%}$ Salinity & \multicolumn{2}{c}{ Stage } & $\mathbf{2}-\mathbf{0 . 9} \%$ Salinity & \multicolumn{3}{c}{ Stage 3-0.4\% Salinity } \\
\cline { 2 - 10 } & Exp. & CFD & \% Error & Exp. & CFD & \% Error & Exp. & CFD & \% Error \\
\hline Ice Salinity (\%) & 0.90 & 0.73 & 18.78 & 0.40 & 0.33 & 17.75 & 0.10 & 0.08 & 17.00 \\
Brine Salinity (\%) & 1.50 & 1.70 & 13.60 & 0.90 & 0.96 & 6.56 & 0.40 & 0.43 & 6.62 \\
Volume Ice (mL) & 55.00 & 46.71 & 15.07 & 70.00 & 64.29 & 8.16 & 75.00 & 72.73 & 3.03 \\
\hline
\end{tabular}

It is also seen in Figure 19 and Table 5, for cases done with and without the mesh respectively, that in the third stage of freezing, 2.6 times more volume of ice was produced for the case with the mesh in comparison to the case without the mesh.

\section{CFD Parametric Analysis-Flow Rate}

The validated CFD model was used to carry out parametric analysis to investigate the effect of $\mathrm{LN}_{2}$ flow rate on the produced volume of ice. Figure 21 shows the volume of ice at various inlet $\mathrm{LN}_{2}$ velocities ranging from 0.0001 to $0.016 \mathrm{~m} / \mathrm{s}$. It can be seen that the volume of ice increased with the increase of $\mathrm{LN}_{2}$ velocity.

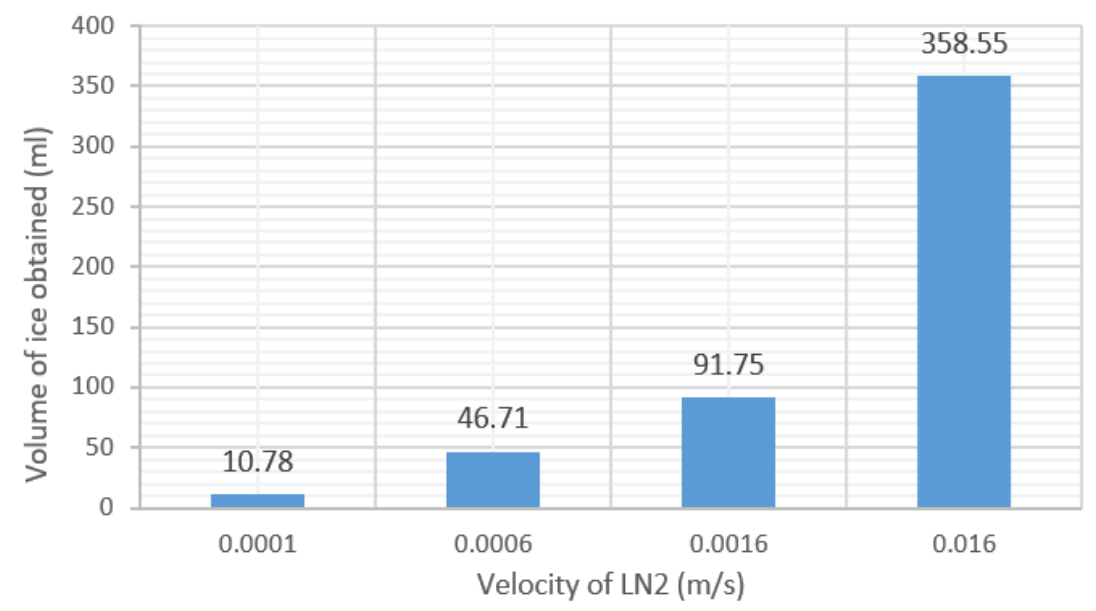

Figure 21. Volume of ice obtained at different $\mathrm{LN}_{2}$ velocities. 
Figure 21 shows that for $0.0001 \mathrm{~m} / \mathrm{s}$ and $0.0006 \mathrm{~m} / \mathrm{s}$ of $\mathrm{LN}_{2}$ velocities, a volume of $10.78 \mathrm{~mL}$ and $46.71 \mathrm{~mL}$ of ice were obtained, respectively. Therefore, increasing the velocity of $\mathrm{LN}_{2}$ by 6 times, increased the volume of ice by about 4.3 times. For $0.0016 \mathrm{~m} / \mathrm{s}$ velocity of liquid nitrogen, the volume of ice obtained was $91.75 \mathrm{~mL}$, producing $96.42 \%$ more ice in comparison to the $0.0006 \mathrm{~m} / \mathrm{s}$ velocity of $\mathrm{LN}_{2}$. Moreover, for $0.016 \mathrm{~m} / \mathrm{s}$ velocity of $\mathrm{LN}_{2}$, it is seen that a greater volume of ice of about $358.55 \mathrm{~mL}$ was obtained, which was about 3.91 times more than the volume obtained at $0.0016 \mathrm{~m} / \mathrm{s}$ velocity of $\mathrm{LN}_{2}$. This is due to the fact that, as the flow rate is increased, $\mathrm{LN}_{2}$ travels further along the copper tube before being fully evaporated and thus reducing the temperature at a large area of the copper tube. Figures 22 and 23 display the liquid phase fraction contours for 0.0001 and 0.0006 of $\mathrm{LN}_{2}$ velocity, respectively. It is seen that by increasing the velocity of $\mathrm{LN}_{2}$, the $\mathrm{LN}_{2}$ travels further along the copper tube before being evaporated and thus producing more ice.

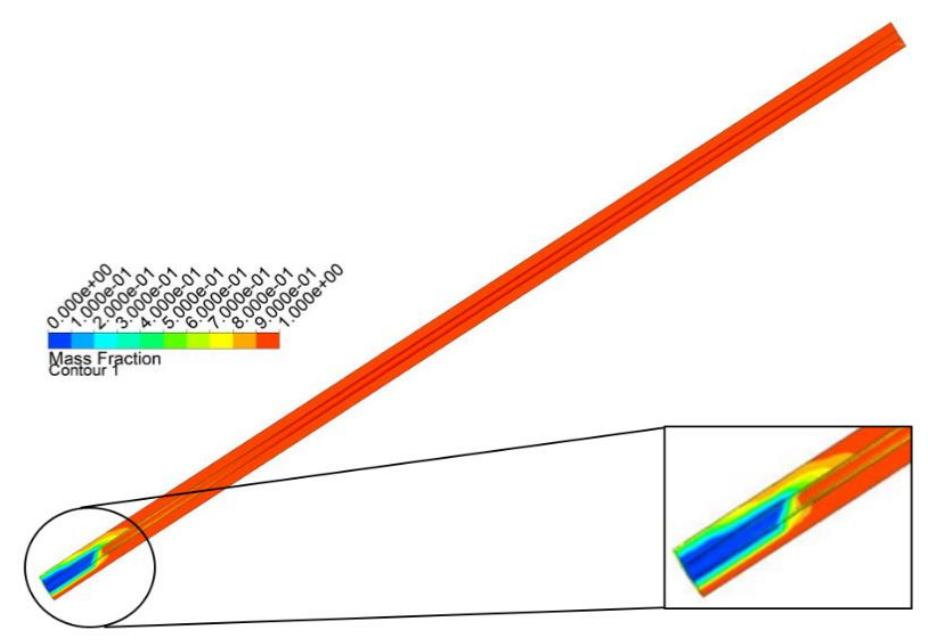

Figure 22. $\mathrm{LN}_{2}$ velocity of $0.0001 \mathrm{~m} / \mathrm{s}$ : liquid phase fraction contours.

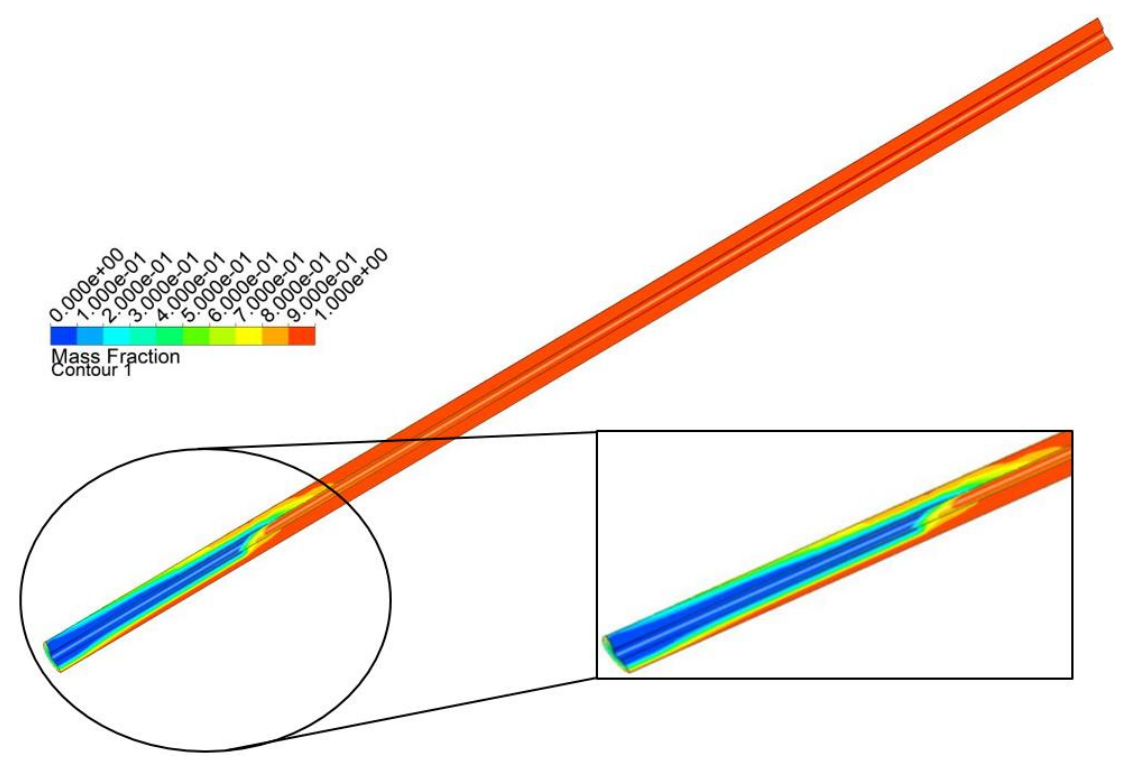

Figure 23. $\mathrm{LN}_{2}$ velocity of $0.0006 \mathrm{~m} / \mathrm{s}$ : liquid phase fraction contours.

Therefore, it can be concluded that, by increasing the velocity of $\mathrm{LN}_{2}$, more ice would be generated, and thus more water could be desalinated due to the fact that the $\mathrm{LN}_{2}$ travels further along the copper tube before being evaporated. However, increasing the velocity means that the $\mathrm{N}_{2}$ outlet conditions will have a higher amount of cold energy. 


\section{Conclusions}

This work investigated numerically and experimentally the feasibility of using cryogenic energy by the evaporation of liquid nitrogen for indirect freeze desalination. Computational fluid dynamics have been used to simulate the evaporation of liquid nitrogen to provide the cooling required for freeze desalination. The main physics used in the modelling process were multiphase, solidification/melting, species transport and energy to develop a CFD model for the evaporation of liquid nitrogen to conduct freeze desalination. This CFD model predicted the surface temperatures of the copper tube, the final ice and brine salinities and the volume of ice produced. A heat exchanger test rig was built to evaporate liquid nitrogen while simultaneously freezing seawater in order to validate the CFD model. The CFD results were compared to experimental showing good agreement, where the average surface temperature deviation was $6.3 \mathrm{~K}$, and the percentage errors for ice, brine and volume of ice were $17 \%$, $6.62 \%$ and $3.03 \%$, respectively.

Two experiments were conducted with and without a mesh being inserted in order to enhance the heat transfer. Inserting the copper mesh improved the heat transfer to a great deal, producing more ice and more desalinated water. The percentage of energy lost by water (overall efficiency) from liquid nitrogen to form ice increased significantly for the test with the mesh; it was $70 \%$ for the test with the mesh and only $21 \%$ for the test without the mesh. The heat exchanger effectiveness improved considerably when the mesh was inserted as it increased by about 4 times for the test with the mesh in comparison to the test carried out without using a mesh.

Three stages of freezing were done in order to bring the ice salinity of $1.5 \%$ down to $0.1 \%$, which is stated as safe to drink by the WHO [40]. It was also concluded that, the initial salinity of salt water had a significant effect on the volume of ice produced and the rate of freezing. Liquid nitrogen $(0.5 \mathrm{~L})$ was evaporated with $104 \mathrm{~kJ}$ of energy consumption to freeze $450 \mathrm{~mL}$ of salt water in order to obtain a volume of 150, 170 and $200 \mathrm{~mL}$ of pure water in the first, second and third freezing stages, respectively, to bring the ice salinity below $0.1 \%$.

Parametric study was then carried out by changing the liquid nitrogen flow rate to observe the volume of ice obtained. When increasing the velocity of $\mathrm{LN}_{2}$ by 6 times, the volume of ice obtained increased by 4.3 times. It was concluded that by increasing the constant velocity of $\mathrm{LN}_{2}$, more volume of ice was generated due to $\mathrm{LN}_{2}$ travelling further along the copper tube before being evaporated, leading to lower surface temperatures and higher rate of freezing. Hence, the above results illustrate the potential of using the cold energy of cryogenic fluids such as $\mathrm{LNG}$ and $\mathrm{LN}_{2} / \mathrm{L}_{\mathrm{Air}}$ for freeze desalination applications, as most cold energy during LNG regasification has been unexploited today.

Author Contributions: Conceptualization, H.J., R.A.-D. and S.M.; Methodology, H.J.; Software, H.J.; Validation, H.J.; Formal Analysis, H.J.; Investigation, H.J.; Resources, R.A.-D. and S.M.; Data Curation, H.J.; Writing-Original Draft Preparation, H.J.; Writing-Review \& Editing, H.J.; Visualization, H.J.; Supervision, R.A.-D. and S.M.; Project Administration, R.A.-D. and S.M.; Funding Acquisition, R.A.-D. and S.M. All authors have read and agreed to the published version of the manuscript.

Funding: This research received no external funding.

Acknowledgments: The author (Harith Jayakody) would like to graciously thank the School of Mechanical Engineering, University of Birmingham, UK; for offering a PhD scholarship to carry out research on the investigation of using cryogenic energy for freeze desalination. The authors appreciatively acknowledge the support of the Engineering and Physical Sciences Research Council (EPSRC) for establishing the Cryogenic Research Facility at UoB (Grant NO. EP/LO17725/1).

Conflicts of Interest: The authors declare no conflict of interest. 


\section{Nomenclature}

\section{Symbols}

A surface area $\left(\mathrm{m}^{2}\right)$

$A_{\text {mush }} \quad$ mushy zone constant (-)

$C_{\text {min }} \quad$ smaller heat capacity (J.kg/K.s)

$C p_{1} \quad$ initial specific heat capacity $(\mathrm{J} / \mathrm{K})$

$C p_{2} \quad$ final specific heat capacity $(\mathrm{J} / \mathrm{K})$

$D_{i, m} \quad$ mass diffusion coefficient for species $\left(\mathrm{m}^{2} / \mathrm{s}\right)$

$\mathrm{E}_{L N 2} \quad$ total energy in a known volume of liquid nitrogen (J)

$\vec{F} \quad$ body force (N)

$\vec{F}_{S} \quad$ solutal buoyancy body forces $(\mathrm{N})$

$\vec{g} \quad$ gravity $\left(\mathrm{m} / \mathrm{s}^{2}\right)$

$H \quad$ enthalpy [energy/mass $(\mathrm{J} / \mathrm{kg})$, energy/mole $(\mathrm{J} / \mathrm{mol})]$

$H_{1} \quad$ inlet enthalpy $(\mathrm{J} / \mathrm{kg})$

$\mathrm{H}_{2} \quad$ outlet enthalpy $(\mathrm{J} / \mathrm{kg})$

$\vec{J}_{i} \quad$ diffusion flux of the species $\left(\mathrm{kg} / \mathrm{m}^{2}-\mathrm{s}\right)$

$k_{e f f} \quad$ effective conductivity (W/m-K)

$K_{i} \quad$ partition coefficient of the solute (-)

$L \quad$ latent heat $(\mathrm{J} / \mathrm{kg})$

$L_{f} \quad$ latent heat of fusion $(\mathrm{J} / \mathrm{kg})$

$m \quad$ mass $(\mathrm{kg})$

$\dot{m} \quad$ mass flow rate $(\mathrm{kg} / \mathrm{s})$

$\dot{m}_{q p} \quad$ rate of mass transfer from phase $\mathrm{q}$ to phase $\mathrm{p}(\mathrm{kg} / \mathrm{s})$

$\dot{m}_{p q} \quad$ rate of mass transfer from phase $\mathrm{p}$ to phase $\mathrm{q}(\mathrm{kg} / \mathrm{s})$

$m_{i} \quad$ slope of the liquidus surface $(\mathrm{K})$

$n \quad$ number of phases (-)

$N_{S} \quad$ number of species (-)

$\mathrm{p} \quad$ pressure $(\mathrm{Pa})$

$\mathrm{Q}_{\text {brine }} \quad$ energy lost by brine remaining $(\mathrm{J})$

$\mathrm{Q}_{\text {ice }} \quad$ energy loss by ice $(\mathrm{J})$

$\mathrm{Q}_{\text {water }} \quad$ energy loss by water $(\mathrm{J})$

$S_{\alpha_{q}} \quad$ source term

$S_{h} \quad$ influences from radiations and any other volumetric heat sources

T temperature (K)

$T_{W 1} \quad$ inlet water temperature $(\mathrm{K})$

$T_{W 2} \quad$ outlet water temperature $(\mathrm{K})$

$T_{N 1} \quad$ inlet nitrogen temperature $(\mathrm{K})$

$T_{N 2} \quad$ inlet nitrogen temperature $(\mathrm{K})$

$\mathrm{U} \quad$ overall heat transfer coefficient $\left(\mathrm{W} / \mathrm{m}^{2} \mathrm{~K}\right)$

$\vec{v} \quad$ velocity $(\mathrm{m} / \mathrm{s})$

$Y_{i} \quad$ mass fraction of the solute (-)

\section{Greek Symbols}

$\begin{array}{ll}\alpha & \text { volume fraction }(-) \\ \beta & \text { liquid volume fraction }(-) \\ \beta_{s, i} & \text { solutal expansion coefficient }\left(\mathrm{K}^{-1}\right) \\ \varepsilon & \text { small number }(0.001)(-) \\ \varepsilon & \text { effectiveness of the heat exchanger }(-) \\ \mu & \text { viscosity of the fluid }(\mathrm{Pa}-\mathrm{s}) \\ \rho & \text { density of fluid }\left(\mathrm{kg} / \mathrm{m}^{3}\right)\end{array}$




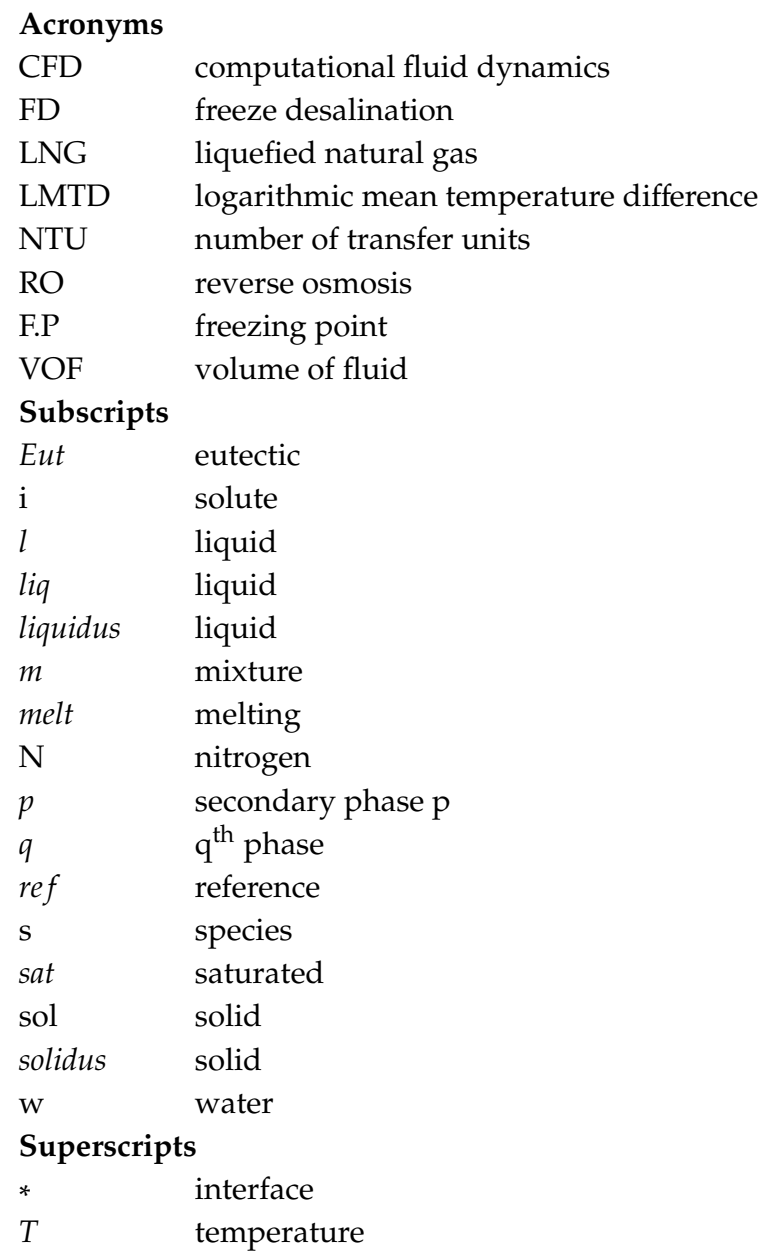

\section{References}

1. Mathioulakis, E.; Belessiotis, V.; Delyannis, E. Desalination by using alternative energy: Review and state-of-the-art. Desalination 2007, 203, 346-365. [CrossRef]

2. Miller, J.E. Review of Water Resources and Desalination Techniques; Unlimited Release Report SAND-2003-0800; Sandia National Labs: Livermore, CA, USA, 2003.

3. Engelman, J.W.R.; Cincotta, R.P.; Dye, B.; Gardner-Outlaw, T. People in the Balance: Population and Natural Resources at the Turn of the Millennium, Population; Population Action International: Washington, DC, USA, 2000.

4. Clarke, M.B.T. Blue Gold: The Fight to Stop the Corporate Theft of the World's Water. Contemp. Hum. Ecol. 2004, 11, 67-71.

5. White, P.H.G.G.F. Water in Crisis: A Guide to the World's Fresh Water Resources. Clim. Chang. 1993, 31, 119-122.

6. March, H. The politics, geography, and economics of desalination: A critical review. Wiley Interdiscip. Rev. Water 2015, 2, 231-243. [CrossRef]

7. Jayakody, H.; Al-Dadah, R.; Mahmoud, S. Numerical investigation of indirect freeze desalination using an ice maker machine. Energy Convers. Manag. 2018, 168, 407-420. [CrossRef]

8. Burn, S.; Hoang, M.; Zarzo, D.; Olewniak, F.; Campos, E.; Bolto, B.; Barron, O. Desalinationtechniques-A review of the opportunities for desalination in agriculture. Desalination 2015, 364, 2-16. [CrossRef]

9. Randall, D.G.J.N. A Succinct Review of the Treatment of Reverse Osmosis Brines Using Freeze Crystallization. J. Water Process Eng. 2015, 8, 186-194. [CrossRef]

10. Fujioka, R.; Wang, L.P.; Dodbiba, G.; Fujita, T. Application of progressive freeze-concentration for desalination. Desalination 2013, 319, 33-37. [CrossRef] 
11. Attia, A.A.A. New proposed system for freeze water desalination using auto reversed R-22 vapor compression heat pump. Desalination 2010, 254, 179-184. [CrossRef]

12. Williams, P.M.; Ahmad, M.; Connolly, B.S.; Oatley-Radcliffe, D.L. Technology for freeze concentration in the desalination industry. Desalination 2015, 356, 314-327. [CrossRef]

13. Lu, Z.; Xu, L. Freezing Desalination Process. Desalin. Water Resour. 2014, 2, 275-290.

14. Cao, W.; Beggs, C.; Mujtaba, I.M. Theoretical approach of freeze seawater desalination on flake ice maker utilizing LNG cold energy. Desalination 2014, 355, 22-32. [CrossRef]

15. Curran, H.M. Water desalination by indirect freezing. Desalination 1970, 7, 273-284. [CrossRef]

16. Lin, W.; Huang, M.; Gu, A. A seawater freeze desalination prototype system utilizing LNG cold energy. Int. J. Hydrog. Energy 2017, 42, 18691-18698. [CrossRef]

17. Jayakody, H.; Al-Dadah, R.; Mahmoud, S. Computational fluid dynamics investigation on indirect contact freeze desalination. Desalination 2017, 420, 21-33. [CrossRef]

18. Ratkje, S.K.; Flesland, O. Modelling the freeze concentration process by irreversible thermodynamics. J. Food Eng. 1995, 25, 553-568. [CrossRef]

19. Qin, F.G.F.; Chen, X.D.; Farid, M.M. Growth kinetics of ice films spreading on a subcooled solid surface. Sep. Purif. Technol. 2004, 39, 109-121. [CrossRef]

20. Qin, F.G.F.; Chen, X.D.; Free, K. Freezing on subcooled surfaces, phenomena, modeling and applications. Int. J. Heat Mass Transf. 2009, 52, 1245-1253. [CrossRef]

21. Qin, F.G.F.; Zhao, J.; Russell, A.; Chen, X.; Chen, J.; Robertson, L. Simulation and Experiment of the Unsteady Heat Transport in the Onset Time of Nucleation and Crystallization of Ice from the Subcooled Solution. Int. J. Heat Mass Transf. 2003, 46, 3221-3231. [CrossRef]

22. Chivavava, J.; Rodriguez-Pascual, M.; Lewis, A.E. Effect of operating conditions on ice characteristics in continuous eutectic freeze crystallization. Chem. Eng. Technol. 2014, 37, 1314-1320. [CrossRef]

23. Genceli, F.E.; Pascual, M.R.; Kjelstrup, S.; Witkamp, G.-J. Coupled Heat and Mass Transfer during Crystallization of $\mathrm{MgSO}_{4} \cdot 7 \mathrm{H}_{2} \mathrm{O}$ on a Cooled Surface. Cryst. Growth Des. 2009, 9, 1318-1326. [CrossRef]

24. Abid, A.J.; Safi, M.J. Simulation of Binary Mixture Freezing: Application to Seawater Desalination. Int. J. Eng. Sci. Innov. Technol. 2015, 4, 158-163.

25. Lim, Y.; Al-Atabi, M.; Williams, R.A. Liquid air as an energy storage: A review. J. Eng. Sci. Technol. 2016, 11, 496-515.

26. Antonelli, M.; Desideri, U.; Giglioli, R.; Paganucci, F.; Pasini, G. Liquid air energy storage: A potential low emissions and efficient storage system. Energy Procedia 2016, 88, 693-697. [CrossRef]

27. Morgan, R.; Nelmes, S.; Gibson, E.; Brett, G. Liquid air energy storage-Analysis and first results from a pilot scale demonstration plant. Appl. Energy 2015, 137, 845-853. [CrossRef]

28. Ahmad, A.; Al-Dadah, R.; Mahmoud, S. Liquid nitrogen energy storage for air conditioning and power generation in domestic applications. Energy Convers. Manag. 2016, 128, 34-43. [CrossRef]

29. Khalil, K.M.; Ahmad, A.; Mahmoud, S.; Al-Dadah, R.K. Liquid air/nitrogen energy storage and power generation system for micro-grid applications. J. Clean. Prod. 2017, 164, 606-617. [CrossRef]

30. Ahmad, A.; Al-Dadah, R.; Mahmoud, S. Liquid air utilization in air conditioning and power generating in a commercial building. J. Clean. Prod. 2017, 149, 773-783. [CrossRef]

31. Ahmad, A.; Al-Dadah, R.; Mahmoud, S. Air conditioning and power generation for residential applications using liquid nitrogen. Appl. Energy 2016, 184, 630-640. [CrossRef]

32. Strahan, D. Dearman. 2017. Available online: http://dearman.co.uk/wp-content/uploads/2017/11/Dearman Company_brochure_301017_web.pdf (accessed on 31 October 2018).

33. Chang, J.; Zuo, J.; Lu, K.J.; Chung, T.S. Freeze desalination of seawater using LNG cold energy. Water Res. 2016, 102, 282-293. [CrossRef]

34. ANSYS Fluent. ANSYS Fluent Theory Guide, 15th ed.; ANSYS: Canonsburg, PA, USA, 2013; Volume 15317, pp. 724-746.

35. Voller, V.R.; Prakash, C. A fixed grid numerical modelling methodology for convection-diffusion mushy region phase-change problems. Int. J. Heat Mass Transf. 1987, 30, 1709-1719. [CrossRef]

36. Voller, V.R.; Brent, A.D.; Prakash, C. The modelling of heat, mass and solute transport in solidification systems. Int. J. Heat Mass Transf. 1989, 32, 1719-1731. [CrossRef]

37. ANSYS Fluent. 2018. Available online: https://www.ansys.com/en-gb/products/fluids/ansys-fluent (accessed on 23 November 2019). 
38. Hartwig, J.; Hu, H.; Styborski, J.; Chung, J.N. Comparison of cryogenic flow boiling in liquid nitrogen and liquid hydrogen chilldown experiments. Int. J. Heat Mass Transf. 2015, 88, 662-673. [CrossRef]

39. Handheld Meter, O.M.E.G.A. Engineering, Handheld Salinity Meter. 2017. Available online: Omega.co.uk (accessed on 23 November 2019).

40. US Environmental Protection Agency, Water-Quality Criteria, Standards, or Recommended Limits for Selected Properties and Constituents. 1994. Available online: https://pubs.usgs.gov/wri/wri024094/pdf/ mainbodyofreport-3.pdf (accessed on 14 December 2017).

41. American Society of Heating Refrigerating and Air-Conditioning Engineers. 2009 Ashrae Handbook: Fundamentals, S-I, ed.; ASHRAE: New York, NY, USA, 2009.

42. Salinity. Available online: http://www.epa.sa.gov.au/environmental_info/water_quality/threats/salinity (accessed on 14 December 2017).

43. Williams, P.M.; Ahmad, M.; Connolly, B.S. Freeze desalination: An assessment of an ice maker machine for desalting brines. Desalination 2013, 308, 219-224. [CrossRef]

(C) 2019 by the authors. Licensee MDPI, Basel, Switzerland. This article is an open access article distributed under the terms and conditions of the Creative Commons Attribution (CC BY) license (http://creativecommons.org/licenses/by/4.0/). 